\title{
Impacto de la fauna exótica doméstica en la subsistencia humana en la cuenca superior del río Limay: la evidencia de Casa de Piedra de Ortega (Río Negro, Argentina)
}

\author{
Ailín A. Guillermo*, Fernando J. Fernández"**** José A. \\ Cordero*: \\ Recibido: \\ 8 de marzo de 2019 \\ Aceptado: \\ 5 de julio de 2019
}

\begin{abstract}
Resumen
Se presenta el estudio zooarqueológico del sitio Casa de Piedra de Ortega, ubicado en la cuenca superior del río Limay (Río Negro, Argentina). Se analizan los conjuntos del componente prehispánico inmediatamente anterior al contacto (Período III, $1490 \pm$ $70 \mathrm{AP}$ ) y del componente posthispánico (Período IV-V, $280 \pm 50 \mathrm{AP}$ ). Se determinó una baja incidencia de meteorización, erosión y acción de carnívoros, lo que indicó buena conservación y rápido enterramiento de los conjuntos. Gran parte de los restos se depositaron por actividad humana, incluyendo la explotación de fauna autóctona y exótica para alimentación y uso de las pieles. A lo largo de toda la secuencia (Períodos III a V) se explotaron Lama guanicoe, Rhea pennata y Conepatus chinga, aunque $L$. guanicoe se configura como el principal recurso. En el Período IV, Lycalopex griseus, Lycalopex culpaeus y Chaetophractus villosus se incorporan a los recursos. En el Período V, se registró la utilización de Equus caballus, Bos taurus y, mayormente, de Ovis aries. Si bien se observó una diversificación taxonómica en las ocupaciones posthispánicas, también se registró una mayor intensidad en la explotación de L. guanicoe. Ello demuestra que no hubo un reemplazo de la explotación de la fauna autóctona con la llegada de la fauna exótica doméstica. Para contextualizar la investigación se utilizó la información procedente de fuentes documentales y se compararon los resultados con los obtenidos en análisis arqueofaunísticos realizados en sitios arqueológicos del área de estudio.
\end{abstract}

* CONICET - Grupo de Estudios en Arqueometría, Facultad de Ingeniería, Universidad de Buenos Aires (UBA). Av. Paseo Colón 850 (CP C1063ACV) Ciudad Autónoma de Buenos Aires, Argentina. E-mail: ailin.guillermo@gmail.com, agustincordero74@yahoo.com.ar

**Cátedra de Zooarqueología, Facultad de Ciencias Naturales y Museo, Universidad Nacional de La Plata (UNLP). Calle 64 s/n entre diagonal 113 y calle 120 (CP B19ooFWA) La Plata, Buenos Aires, Argentina. E-mail: fernandezf7@@yahoo.com.ar

\section{Palabras clave}

Zooarqueología Transición pre y posthispánica Subsistencia

Noroeste de Patagonia 
Impact of domestic exotic fauna on human subsistence in the upper Limay river basin: the evidence from Casa de Piedra de Ortega (Río Negro, Argentina)

\begin{abstract}
Keywords

Zooarchaeology

Pre and post- Hispanic transition

Subsistence

Northwest of Patagonia

We present the zooarchaeological study of the Casa de Piedra de Ortega site, located in the upper basin of the Limay River (Rio Negro Province, Argentina). We analyze the assemblages coming from the pre-Hispanic component (Period III, $1490 \pm 70$ C14 BP, immediately before contact), and the post-Hispanic component (Periods IV-V, $280 \pm 50$ C14 BP). A low incidence of weathering, erosion, and carnivore action was identified indicating good preservation and rapid burial of the assemblages. Most of the remains were deposited by human activities, including the exploitation of native and exotic fauna for feeding and skin use. Throughout the sequence (Periods III to V) Lama guanicoe, Rhea pennata, and Conepatus chinga were exploited, although L. guanicoe was the main resource. In Period IV, Lycalopex griseus, Lycalopex culpaeus, and Chaetophractus villosus were incorporated into the diet. In Period V, the use of Equus caballus, Bos taurus, and mostly of Ovis aries was recorded. Although a taxonomic diversification was observed in posthispanic occupations, there was also an increase in the intensity of L. guanicoe exploitation. This shows that there was no replacement of native fauna exploitation with the arrival of domestic exotic fauna. Information from documentary sources was used to contextualize this research and the results were compared with those from archaeofaunistic analyzes carried out at other archaeological sites in the study area.
\end{abstract}

\section{Introducción}

En el presente trabajo se dan a conocer las características del impacto de las especies exóticas domésticas (Equus caballus, Ovis aries y Bos taurus) en la subsistencia de los grupos humanos en el sitio arqueológico Casa de Piedra de Ortega (en adelante CPO). Para ello se identificará la composición taxonómica de los conjuntos arqueofaunísticos, se evaluará la resolución e integridad de los mismos, se explorarán los patrones de obtención, procesamiento, consumo y descarte y se reconocerán las diferencias en el aprovechamiento de la fauna exótica doméstica y la autóctona. Finalmente, se utilizarán las principales fuentes documentales de Norpatagonia que mencionen el aprovechamiento de la fauna exótica doméstica. Asimismo, se compararán los resultados de esta investigación con otros análisis zooarqueológicos realizados en sitios de la cuenca superior y media del río Limay.

Los estudios arqueofaunísticos realizados en Patagonia presentan un amplio desarrollo (Borrero, 1981, 1990, 1995; Cordero, 2009, 2011, 2012; Fernández, P., 2001, 2008; Fernández, F. et al., 2016; Hajduk, Scartascini, Vargas y Lezcano, 2018; Mengoni Goñalons, 1988, 1999, 2006; Miotti, 2012; Rindel, 2017; Silveira y Cordero, 2014, por ejemplo). Sus aportes se centran en aspectos tales como la movilidad y la subsistencia de los cazadores-recolectores basados en la explotación de Lama guanicoe (guanaco) como recurso principal -obtención de carne y de materia prima- durante el Pleistoceno tardío y Holoceno. En los últimos años, creció el interés por el estudio de faunas de porte menor y se demostró la utilización de estos recursos como complemento en la dieta de los cazadores-recolectores hacia el Holoceno tardío (Cordero, 2009, 2011, 2012; Fernández, F. et al., 2016; Fernández, Teta y Pardiñas, 2017a; Guillermo, Fernández y Cordero, 2019; Pardiñas, 1999a; Rindel, 2017, por ejemplo). A pesar de que en el noroeste de esta región se desarrollaron muchos trabajos zooarqueológicos, aún son 
escasos los estudios que aporten información sobre los usos de la fauna exótica y el impacto en la subsistencia humana (Hajduk y Albornoz, 1999; Hajduk et al., 2018; Silveira y Cordero, 2014). En el bosque, los análisis señalan el uso de la fauna exótica como alimento y la presencia temprana de caballos (Equus caballus) hacia finales del siglo XVI (Albornoz y Hajduk, 2009; Hajduk y Albornoz, 1999). El único análisis zooarqueológico en el área de la estepa en el noroeste de Patagonia, sostiene el uso de caballo y oveja (Ovis aries) como alimento por parte de los indígenas en el siglo XVIII (Silveira y Cordero, 2014).

Consideramos que los conjuntos arqueofaunísticos procedentes de CPO son potenciales para conocer el impacto de la fauna exótica doméstica y ampliar el conocimiento sobre las transformaciones en la subsistencia de los grupos humanos en la cuenca superior y media del río Limay durante la transición de los períodos prehispánico y posthispánico.

\section{Área de estudio y sitio arqueológico}

CPO está ubicado en el paraje Corralito, Departamento Pilcaniyeu, provincia de Río Negro (4043’49” Sur, 70²'21" Oeste, 675 m s.n.m. ). Se encuentra sobre un afloramiento de tobas de la Formación Collón Cura cerca de la confluencia del arroyo Panquehuau con el arroyo Pichileufú, en la zona de estepa (Figura 1).

El clima es árido. La precipitación anual media es de $250 \mathrm{~mm}$. La temperatura anual media es de $10 \mathrm{a} 14^{\circ} \mathrm{C}$. Domina el viento del sector oeste y sudoeste. Fitogeográficamente, pertenece a una área de mosaico entre la estepa arbustiva-graminosa del Distrito Occidental, la estepa arbustiva del Distrito Central y la estepa arbustiva del Ecotono Rionegrino (León, Bran, Collantes, Paruelo y Soriano, 1998).

En el nordeste crecen arbustos tales como Chuquiraga avellanedae y Nassauvia axillaris. Hacia el sur y la cordillera, la estepa arbustiva se transforma en una estepa de gramíneas, representadas por Stipa speciosa y Stipa humilis. En el noroeste dominan las gramíneas y arbustos, entre los últimos Mulinum spinosum. El Ecotono Rionegrino se caracteriza por elementos del Monte, como Prosopis denudans, Schinus polygamus y Larrea nitida, junto con flora patagónica (León et al., 1998).

Se trata de un sitio compuesto que está formado por una cueva de unos $20 \mathrm{~m}^{2}$ cubiertos, orientada al oeste y una extensión a cielo abierto (CPO2). Los estratos de CPO se agruparon en cinco períodos cronológicos que se suceden desde ca. $2800 \mathrm{AP}$ hasta la última conquista militar (Tabla 1).

Las investigaciones en CPO se realizaron en el marco del proyecto Salvataje Arqueológico e Investigaciones Prehistóricas en el Área de Alicurá dirigido por la Dra. Amalia C. Sanguinetti de Bórmida (Fernández, M., 2001). Se llevaron a cabo tres campañas de excavación en 1983, 1985 y 1986. Se hallaron restos faunísticos de taxones autóctonos y exóticos, restos líticos como raspadores, puntas de proyectil y desechos de talla (mayormente en sílice), abundantes estructuras de combustión, instrumentos óseos, cerámica, adornos personales y elementos europeos (Fernández, M., 2001).

Los primeros tres períodos comprenden las ocupaciones humanas en tiempos prehispánicos. El Período IV se ubica cronológicamente hacia fines del siglo XVII y principios del siglo XVIII, pero no se le asocia ningún elemento europeo. El Período $\mathrm{V}$ representa las últimas ocupaciones y es el único que tiene asociado elementos europeos tales como cuentas de vidrio. La presencia de lentes de fogones, cenizas y cubetas testimonian que a partir de los 2000 años la cueva se ocupó reiteradas veces y con intensidad. En correspondencia, la cerámica está presente a partir de ese momento 


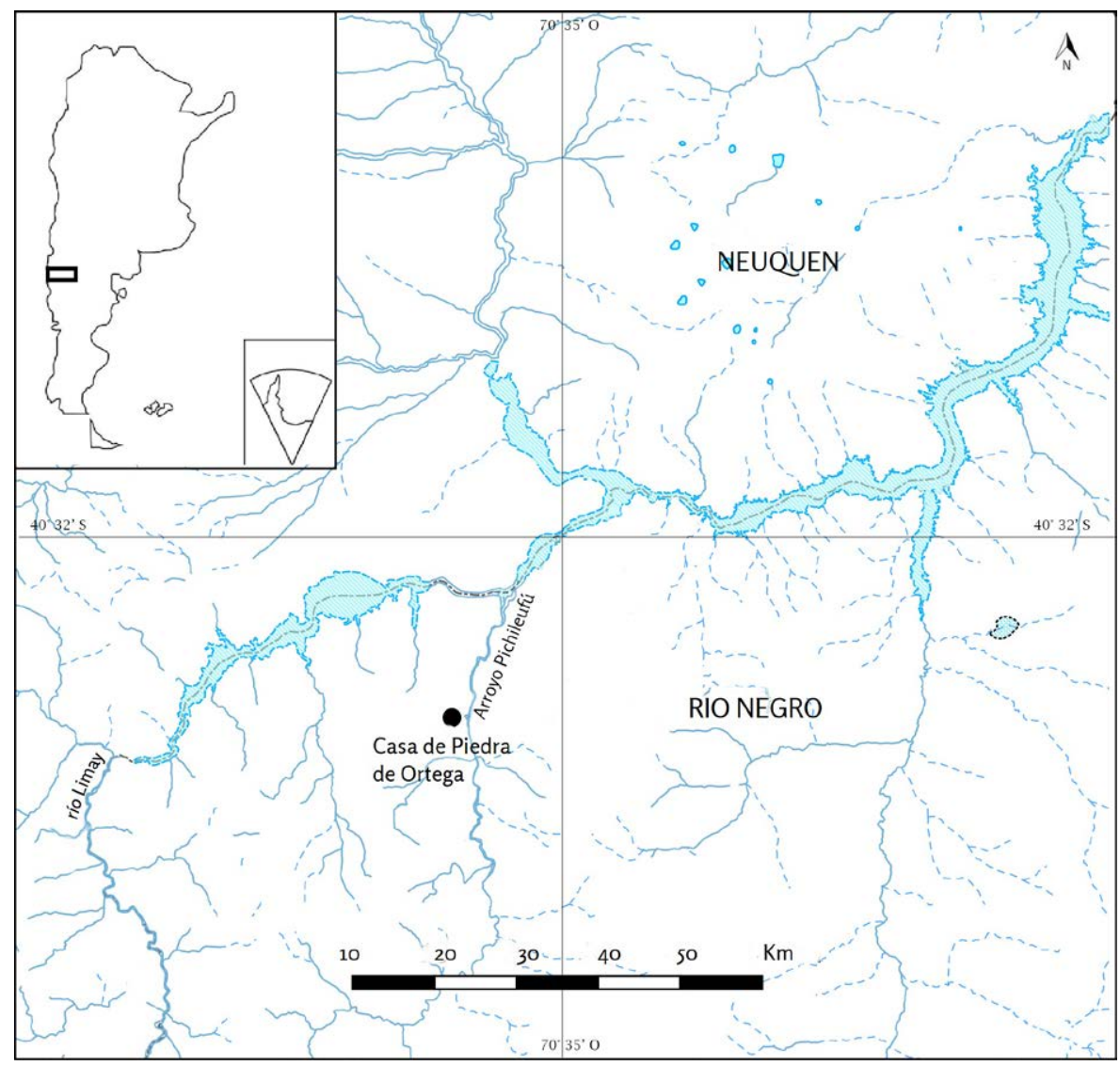

Figura 1. Mapa con la ubicación del sitio arqueológico Casa de Piedra de Ortega.

\begin{tabular}{|c|c|c|}
\hline Estratos & $\begin{array}{l}\text { Cronología } \\
\text { (años }{ }^{14} \text { C AP) }\end{array}$ & Períodos \\
\hline \#b1 & Posthispánico & V \\
\hline \#b2 & \multirow{2}{*}{$\begin{array}{c}280 \pm 50 \\
(L P 191)\end{array}$} & \multirow{2}{*}{ IV } \\
\hline \#C2 & & \\
\hline \#C3 & \multirow{5}{*}{$\begin{array}{c}1490 \pm 70 \\
(\mathrm{LP} 1320)\end{array}$} & \multirow{5}{*}{ III } \\
\hline \#c4 & & \\
\hline Tefras & & \\
\hline$\# d$ & & \\
\hline$\# \mathrm{e}_{1}$ & & \\
\hline \# 2 & \multirow{3}{*}{$\begin{array}{c}2000 \pm 90 \\
(\mathrm{LP} 168)\end{array}$} & \multirow{3}{*}{ II } \\
\hline$\# f$ & & \\
\hline \#g & & \\
\hline$\# \mathrm{~h}$ & \multirow{2}{*}{$\begin{array}{c}2710 \pm 100 \\
(\text { AC 951) }\end{array}$} & \multirow{2}{*}{ I } \\
\hline$\# \mathrm{i}$ & & \\
\hline
\end{tabular}

Tabla 1. Relación entre estratos, cronología y períodos en Casa de Piedra de Ortega. Todos los fechados se realizaron sobre muestras de carbón vegetal. 
(Fernández, M., 2001; Fernández y Vitores, 2009). En general, la cerámica es lisa con escasa decoración, tiene pastas y acabados superficiales grises o pardos (Fernández y Vitores, 2009). El estrato \#b2 pertenece a las últimas ocupaciones previas al contacto hispano-indígena. Los estratos que siguen -\#b1 y guano superficial- se formaron ya en época de interacción entre los indígenas y la sociedad europea, según lo indican la aparición de cuentas de vidrio (Fernández, M., 2001). La zona central de la cueva se utilizó para realizar actividades domésticas, como preparación de alimentos y de cueros en los períodos III, IV y V(Crivelli y Fernández, 2010; Fernández y Crivelli, 1999, 2003).

A lo largo de la secuencia de ocupación y, con un aumento considerable en el período posthispánico, se recuperaron 85 adornos personales y artefactos decorados confeccionados mayormente en huesos indeterminados, en valvas y en piedras (Fernández y Ramos, 2009). Los estudios zooarqueológicos previos se han centrado sobre el análisis de los micromamíferos de los estratos inferiores de CPO (\#i, \#h y \#g) (Pardiñas, 1999a, 1999b; Teta, Andrade y Pardiñas, 2005), no analizados en este trabajo. En estos niveles, los sigmodontinos son poco abundantes y están representados por Reithrodon auritus, Eligmodontia sp., Calomys sp. y Phyllotis xanthopygus (Pardiñas, 1999b). También se registró Akodon cf. A. iniscatus y un orizomino posiblemente perteneciente a la especie Oligoryzomys longicaudatus. Asimismo, son frecuentes Ctenomys sp., Microcavia australis, Galea leucoblephara y el marsupial Lestodelphys halli. El análisis de los restos termoalterados de micromamíferos indicó diferencias entre huesos craneales y postcraneales (Pardiñas, 1999b). La termoalteración se concentró en el extremo distal de los incisivos y de las tibias de roedores caviomorfos, sugiriendo consumo antrópico (e. g., Pardiñas, 1999a, 1999b). A partir de esos resultados se concluyó que los micromamíferos de CPO tuvieron un origen mixto, resultante de la depredación de aves rapaces y consumo antrópico (Pardiñas, 1999a, 1999b).

\section{Metodología}

La identificación y cuantificación anatómica y taxonómica fue realizada a partir de una colección ósea de referencia y un atlas osteológico (Pacheco Torres, Altamirano y Guerra Porras, 1979). Para el grupo Mammalia se estipularon varias categorías de peso corporal: mamíferos pequeños (1-3 kg), mediano-pequeños (3-15 kg), mediano-grandes $(15-50 \mathrm{~kg}$ ) y grandes $(>50 \mathrm{~kg}$ ). Los rangos etarios (juvenil y adulto) se determinaron según el estado de fusión de los elementos anatómicos (Kaufmann, 2009).

La frecuencia taxonómica y de partes esqueletales se calculó mediante el Número de Especímenes Identificados por Taxón (NISP), Número Mínimo de Individuos (MNI), Número Mínimo de Elementos (MNE) y Número Mínimo de Unidades Anatómicas (MAU y MAU\%) (Mengoni Goñalons, 1988, 1999, 2006). Los especímenes que no pudieron identificarse fueron asignados como no identificables (NID). Las cáscaras de huevo de Rhea sp. se contabilizaron separadamente, ya que no forman parte del esqueleto y sobredimensionan la muestra. La abundancia relativa de partes esqueletales se expresó mediante el MAU, que aplicamos solamente para Lama guanicoe y Ovis aries, por ser las especies más representadas de la fauna autóctona y exótica respectivamente (Mengoni Goñalons, 1999). Se calculó también en forma estandarizada (MAU\%) (Binford, 1981; Lyman, 1994).

La frecuencia relativa de partes esqueletales se correlacionó con el índice de utilidad (MGUI) para Lama guanicoe calculado por Borrero (1990, modificado por Lyman, 1992) y para Ovis aries (Binford, 1978), mediante el uso del coeficiente de correlación de Pearson. De este modo, se pudo examinar si las alternativas de transporte selectivo 
explican el patrón de representación observado en las distintas unidades. Se calculó la correlación entre la frecuencia relativa de partes y la densidad mineral ósea para saber si la representación de partes esqueletales del conjunto arqueofaunístico está afectada por la densidad mineral ósea de cada unidad anatómica (Elkin, 1995).

La diversidad taxonómica de cada conjunto se estimó mediante el índice de Shannon sobre la base del MNI (Grayson, 1984; Lyman, 2008). Para evaluar la riqueza taxonómica se calculó el NTaxa (Lyman, 2008) incluyendo sólo los taxones con evidencias de procesamiento antrópico, sin solapar categorías taxonómicas para no sobreestimar la muestra. Se usó el coeficiente de correlación rho de Spearman para caracterizar la relación entre el MAU\% con el índice de utilidad de la carne en Lama guanicoe y Ovis aries, y así estimar si los conjuntos están afectados por el transporte diferencial de partes esqueletales. Se tomaron los rangos planteados por Wolverton y colaboradores (Wolverton, Dombrosky y Lyman, 2016): alto > 0,7, moderado 0,7-0,3 y bajo <0,3. Los cálculos estadísticos se realizaron mediante el programa PAleontological STatistics, versión 3.22 (Hammer, Harper y Ryan, 2001).

Desde una perspectiva tafonómica, se registraron rastros de actividad de carnívoros (pozos y hoyuelos) (Binford, 1981; Fernández-Jalvo y Andrews, 2016), de aves rapaces (tipos de corrosión digestiva: ligera, moderada, alta y extrema) (Fernández, Montalvo, Fernández-Jalvo, Andrews y López, 2017b), de diagénesis (Lyman, 1994) y de agentes meteóricos (Beherensmeyer, 1978). El análisis de estas variables nos permitió informar en qué grado la muestra está afectada por procesos naturales.

En relación con el análisis de las modificaciones antrópicas, se identificaron huellas de corte, raspado, machacado y negativos de impacto (Blumenshine, Marean y Capaldo, 1996; Fernández-Jalvo y Andrews, 2016). Para determinar la finalidad de las huellas se tuvo en cuenta diferentes atributos, como la morfología, frecuencia y distribución de las mismas en la topografía de cada hueso según el análisis realizado por Binford (1981).

El análisis de fracturas nos permitió conocer el modo y el grado del aprovechamiento de las presas (Mengoni Goñalons, 1999; Shipman y Rose, 1983). Se utilizaron las siguientes características: 1) el tipo de fractura primaria en relación con los ejes del hueso (espiral, transversal y longitudinal); 2) el tipo de borde que presenta la fractura (regular, astillado o con marcado perimetral) y 3 ) el estado en que se encontraban los huesos antes de la fractura (fresco/no fresco).

La termoalteración de los restos óseos puede ser consecuencia, por ejemplo, de la cocción, de su descarte, de su uso como combustible o por fuego de origen natural (Álvarez et al., 2017; Costamagno, Théry-Parisot, Brugal y Guibert, 2005; De Nigris, 2004). Para determinar estas acciones se siguió el atributo basado en el color, la textura y su uniformidad sobre la superficie de los elementos (Shipman, Foster y Schoeninger, 1984). Se identificaron 5 grados: no quemado, quemado incipiente, quemado avanzado, carbonizado (negro) y calcinado (blanco azulado). Los grados incipiente y avanzado se caracterizan por un grado bajo de termoalteración de color marrón claro a oscuro y por lo general se ubican en una porción del elementos. El carbonizado presenta un color negro homogéneo y uniforme y se puede observar una textura craquelada sobre la superficie del hueso. El calcinado representa el nivel más alto de termoalteración con un color gris-azulado y con una textura craquelada de mayor grado.

Por último, se utilizaron las principales fuentes documentales del área de estudio para generar hipótesis y para contextualizar la investigación arqueológica (Fernández, M., 2006). También se realizó la comparación de los resultados con los obtenidos en análisis zooarqueológicos realizados en sitios ubicados en el área de estudio. 


\section{Resultados}

Se recuperó un total de 7.020 restos faunísticos (Período III $=1.431$; Período IV = 2.082; Período $\mathrm{V}=3.507)$.

\section{Período III}

Se identificaron 385 restos óseos y 880 se asignaron a NID. Las cáscaras de huevo de Rhea sp. se contabilizaron y suman 166 fragmentos, observándose termoalteración en un $11,4 \%$.

La especie más representada fue Lama guanicoe (NISP\% $=48,6$ ), seguida por Chaetophractus villosus con el 8,3 NISP\% (Tabla 2). Con porcentajes menores se identificaron restos de Diplodon chilensis, Rhea pennata, Conepatus chinga, Leopardus sp. y Zaedyus pichiy. Asimismo, se encontraron restos óseos de Rodentia (NISP\% = 28,1). Entre estos últimos, los roedores caviomorfos son los dominantes, con un $13,5 \%$, incluyendo Galea leucoblephara, Microcavia australis y Ctenomys sp. En términos de MNI, Microcavia australis arrojó el valor más alto, seguido por Lama guanicoe. Los roedores sigmodontinos constituyen el grupo minoritario.

El esqueleto apendicular de Lama guanicoe está representado en un 59,9\% mientras que el esqueleto axial lo está en un 40,1\%. Se encontraron todos los elementos anatómicos, a excepción del sacro y de las vértebras caudales. También, podemos observar un predominio de los huesos largos. A partir del estado de fusión de los elementos óseos de Lama guanicoe se reconoció 1 individuo juvenil y 3 individuos adultos. Al sitio ingresaron mayormente los miembros anteriores y posteriores, seguidos por el cráneo y por pocas porciones de la columna y las costillas (Tabla 3 y 4). En relación con el esqueleto apendicular, el metapodio es el elemento más frecuente, especialmente los fragmentos de diáfisis (Tabla 4). Los miembros anteriores son menos frecuentes respecto con los miembros posteriores. Podemos pensar que los elementos anatómicos rótula, tibia y tarsianos llegaron juntos al sitio debido a la similitud en sus frecuencias. En referencia con la abundancia relativa de partes esqueletarias, observamos que la rótula completa cuenta con la mayor abundancia. La mayor parte del conjunto perteneciente a Lama guanicoe se caracteriza por expresar un MAU\% moderado, entre $30 \%$ y $60 \%$ (Tabla 3 y 4). No se observó una asociación significativa entre los valores de MAU\% con los de densidad ósea (rho de Spearman =0,24184; $\mathrm{p}>0,05$ ). En este sentido, la densidad mineral ósea no es una variable relevante y/o no explica la conservación diferencial del conjunto óseo de Lama guanicoe. Por último, se observó una correlación no significativa y positiva entre los valores del índice de MGUI para Lama guanicoe y el MAU\% (coeficiente de correlación de Pearson = 0,0630; p > 0,05), lo que sugiere que el conjunto no está afectado por el transporte selectivo de partes esqueletales.

Las modificaciones óseas producto de agentes naturales afectaron en menor medida al conjunto (2,33\%) (Tabla 5 y Figura 2). Se observan escasos restos con marcas de carnívoros, adherencias de manganeso, evidencias de erosión y no se han registrado grados elevados de meteorización, ya que la mayoría del conjunto no presenta fisuras o exfoliaciones.

Los especímenes no identificados presentan un mayor y diverso grado de termoalteración respecto de los identificados. Dentro del grupo de alteraciones antrópicas presentes en los restos de los taxones identificados dominan las huellas de corte relacionadas con actividades de descarne. En relación con las fracturas óseas de los especímenes identificados (Tabla 5), la tipo transversal es la más frecuente. El borde astillado es el más representado. Se determinó que un 37,2\% de las fracturas se realizaron en estado fresco en restos de Lama guanicoe, Rhea pennata y Conepatus chinga. 


\begin{tabular}{|c|c|c|c|c|c|c|c|c|c|}
\hline & \multicolumn{3}{|c|}{ Período III } & \multicolumn{3}{|c|}{ Período IV } & \multicolumn{3}{|c|}{ Período V } \\
\hline & NISP & MNE & MNI & NISP & MNE & MNI & NISP & MNE & MNI \\
\hline \multicolumn{10}{|l|}{ Mollusca } \\
\hline Diplodon chilensis & 18 & 1 & 1 & 12 & 1 & 1 & 72 & 3 & 1 \\
\hline Osteichthyes indeterminado & o & - & - & 0 & - & - & 1 & - & - \\
\hline \multicolumn{10}{|l|}{ Aves } \\
\hline Ave pequeña indeterminado & 1 & - & - & 4 & - & - & - & - & - \\
\hline Rhea pennata & 11 & 1 & 1 & 40 & 3 & 2 & 59 & 35 & 2 \\
\hline Mammalia indeterminado & o & - & - & o & - & - & 1 & - & - \\
\hline Mammalia indeterminado (grande) & 1 & - & - & 0 & - & - & 3 & - & - \\
\hline Mammalia indeterminado (mediano-grande) & o & - & - & 2 & - & - & 14 & - & - \\
\hline Mammalia indeterminado (pequeño-mediano) & o & - & - & o & - & - & 4 & - & - \\
\hline Mammalia indeterminado (pequeño) & 5 & - & - & o & - & - & 1 & - & - \\
\hline Cetartiodactyla indeterminado & 9 & & & & & & & & \\
\hline Bos taurus & o & - & - & o & - & - & 6 & 6 & 1 \\
\hline Ovis aries & o & - & - & o & - & - & 95 & 68 & 2 \\
\hline Lama guanicoe & 187 & 70 & 4 & 207 & 68 & 2 & 465 & 123 & 4 \\
\hline \multicolumn{10}{|l|}{ Perissodactyla } \\
\hline Equus caballus & o & - & - & o & - & - & 2 & 1 & 1 \\
\hline \multicolumn{10}{|l|}{ Carnivora } \\
\hline Puma concolor & 0 & - & - & o & - & - & 1 & 1 & 1 \\
\hline Lycalopex griseus & o & - & - & 6 & 1 & 1 & 27 & 16 & 2 \\
\hline Lycalopex culpaeus & o & - & - & 4 & 1 & 1 & 11 & 10 & 2 \\
\hline Leopardus sp. & 1 & 1 & 1 & 3 & 1 & 1 & 10 & 8 & 2 \\
\hline Conepatus chinga & 11 & 2 & 1 & 17 & 4 & 3 & 35 & 21 & 6 \\
\hline \multicolumn{10}{|l|}{ Xenarthra } \\
\hline Chaetophractus villosus & 32 & 1 & 1 & 92 & 1 & 1 & 136 & 29 & 3 \\
\hline Zaedyus pichiy & 1 & 1 & 1 & 25 & 1 & 1 & 13 & 3 & 2 \\
\hline Lagomorpha/Leporidae indeterminado & o & - & - & o & - & - & 1 & - & - \\
\hline Rodentia indeterminado & 54 & - & - & 23 & - & - & 19 & - & - \\
\hline Caviidae indeterminado & 27 & - & - & 1 & - & - & 4 & - & - \\
\hline Galea leucoblephara & 2 & 1 & 1 & 8 & 4 & 6 & 9 & 12 & 5 \\
\hline Microcavia australis & 19 & 19 & 9 & 19 & 6 & 7 & 22 & 8 & 8 \\
\hline Ctenomys sp. & 4 & 2 & 2 & 1 & 1 & 1 & 9 & 8 & 5 \\
\hline Sigmodontinae indeterminado & 2 & - & - & 7 & - & - & o & - & - \\
\hline Reithrodon auritus & o & - & - & 3 & 3 & 2 & 4 & 4 & 4 \\
\hline Eligmodontia sp. & o & - & - & 4 & 2 & 1 & 1 & 1 & 1 \\
\hline Calomys musculinus & 0 & - & - & 3 & 2 & 1 & o & - & - \\
\hline Phyllotis xanthopygus & o & - & - & 2 & 1 & 1 & o & - & - \\
\hline Graomys griseoflavus & o & - & - & 1 & 1 & 1 & o & - & - \\
\hline \multicolumn{10}{|l|}{ Marsupialia } \\
\hline Thylamys pallidior & o & - & - & $\mathrm{o}$ & - & - & 1 & 1 & 1 \\
\hline Total & 385 & 99 & 22 & 484 & 101 & 33 & 1.026 & 164 & 53 \\
\hline
\end{tabular}

Tabla 2. Resultados de cálculos de NISP, MNE y MNI para taxones identificados en los Períodos III, IV y V de Casa de Piedra de Ortega. *placas óseas del exoesqueleto de Chaetophractus villosus incluidas en el NISP: Período III = 23; Período IV = 64; Período V = 96. *"placas óseas del exoesqueleto de Zaedyus pichiy incluidas en el NISP: Período III = 1; Período IV = 25; Período V = 10. 


\begin{tabular}{|c|c|c|c|c|c|c|c|c|c|c|c|c|}
\hline \multirow{2}{*}{ Esqueleto Axial } & \multicolumn{4}{|c|}{ Período III } & \multicolumn{4}{|c|}{ Período IV } & \multicolumn{4}{|c|}{ Período V } \\
\hline & NISP & MNE & MAU & MAU\% & NISP & MNE & MAU & MAU\% & NISP & MNE & MAU & MAU\% \\
\hline Dientes & 9 & - & - & - & 22 & - & - & - & 82 & - & - & - \\
\hline Cráneo: occipital & 4 & 1 & 1 & 50 & 2 & 1 & 1 & 66,7 & 6 & 1 & 1 & 34,8 \\
\hline Cráneo: maxilar & 1 & 1 & 1 & 50 & 9 & 1 & 1 & 66,7 & 5 & 1 & 1 & 34,8 \\
\hline Cráneo: bula & o & o & o & o & 1 & 1 & 0,5 & 33,3 & o & o & o & o \\
\hline Mandíbula & 7 & 2 & 1 & 50 & 5 & 1 & 0,5 & 33,3 & 6 & 6 & 1 & 34,9 \\
\hline Hioides & o & o & o & o & o & o & o & o & 2 & 1 & 0,5 & 17,4 \\
\hline Atlas & 1 & 1 & 1 & 50 & o & $\mathrm{o}$ & o & o & o & o & o & o \\
\hline Axis & 1 & 1 & 1 & 50 & o & o & o & o & o & o & o & o \\
\hline Vértebras cervicales 3-7 & 12 & 3 & 0,6 & 30 & 10 & 5 & 1 & 66,7 & 17 & 4 & 0,8 & 27,9 \\
\hline Vértebras torácicas 1-12 & 3 & 3 & 0,2 & 12,5 & 5 & 3 & 0,2 & 16,7 & 7 & 2 & 0,17 & 5,9 \\
\hline Vértebras lumbares 1-7 & 14 & 1 & 0,1 & 7,1 & 5 & 1 & 0,1 & 9,2 & 6 & 2 & 0,29 & 10,1 \\
\hline Sacro & o & $\mathrm{o}$ & o & o & 3 & 1 & 1 & 66,7 & o & o & o & o \\
\hline Vértebras caudales & o & o & o & o & 2 & 1 & 0,1 & 9,2 & o & o & 0 & o \\
\hline Vértebras indeterminadas & 3 & - & - & - & 3 & - & - & - & 11 & - & - & - \\
\hline Costillas: proximal & 1 & 1 & 0,1 & 2,1 & 2 & 2 & 0,1 & 5,6 & 4 & 4 & 0,17 & 5,9 \\
\hline Costillas: fragmentos & 18 & 2 & 0,1 & 4,2 & 20 & 2 & 0,1 & 5,6 & 64 & 13 & 0,54 & 18,8 \\
\hline Esternón & 1 & 1 & 1 & 50 & o & o & o & o & o & o & o & o \\
\hline Total & 75 & 17 & & & 89 & 19 & & & 210 & 30 & & \\
\hline
\end{tabular}

Tabla 3. Frecuencia de NISP, MNE, MAU y MAU\% del esqueleto axial de Lama guanicoe en el Período III, IV y V de Casa de Piedra de

\section{Período IV}

Se identificaron 484 especímenes (NISP), mientras que 931 no pudieron ser identificados y se asignaron a NID (Tabla 2). Las cáscaras de Rhea sp. suman 667 restos y el 28,8\% presenta termoalteración.

La mayor parte de los restos identificados pertenecen a Lama guanicoe (NISP\% $=42,8$ ), siendo éste el taxón más frecuente en el Período IV. Diplodon chilensis se registró en un $2,47 \%$, Rhea pennata en un $8,3 \%$, Lycalopex griseus en un 1,23\%, Lycalopex culpaeus en un $0,82 \%$, Leopardus sp. en un $0,62 \%$ y Conepatus chinga alcanzó un 3,51\%. Se determinaron dos especies de armadillos, Chaetophractus villosus y Zaedyus pichiy. Se registraron los roedores caviomorfos Galea leucoblephara, Microcavia australis y Ctenomys sp. y escasos cricétidos, incluyendo Reithrodon auritus, Eligmodontia sp, Calomys musculinus, Phyllotis xanthopygus y Graomys griseoflavus (Tabla 2). Los cálculos de MNI mostraron que los roedores cávidos (Microcavia australis y Galea leucoblephara) son los más abundantes (Tabla 2). El tercer taxón más abundante es Conepatus chinga.

El esqueleto apendicular de Lama guanicoe representa un 57\% de los restos asignados a este taxón (Tabla 4). Los huesos más representados son las diáfisis de metapodios y la primera falange. La mayoría de los elementos anatómicos están presentes en el conjunto, a excepción de hioides, atlas, axis, esternón y sesamoideos (Tabla 3 y 4). A partir del estado de fusión de los elementos anatómicos de Lama guanicoe se identificó un individuo juvenil y un individuo adulto en el Período IV. Las rótulas y los metapodios son los elementos anatómicos que cuentan con la mayor frecuencia, mientras que la mayor cantidad de elementos anatómicos de Lama guanicoe presentan un MAU\% moderado de 30 y $60 \%$ (Tabla 3 y 4). Existe una correlación no significativa entre los valores de densidad mineral ósea y MAU\% (rho de Spearman = 0,190; p > 0,05); 


\begin{tabular}{|c|c|c|c|c|c|c|c|c|c|c|c|c|}
\hline \multirow{2}{*}{ Esqueleto apendicular } & \multicolumn{4}{|c|}{ Período III } & \multicolumn{4}{|c|}{ Período IV } & \multicolumn{4}{|c|}{ Período V } \\
\hline & NISP & MNE & MAU & MAU\% & NISP & MNE & MAU & MAU\% & NISP & MNE & MAU & MAU\% \\
\hline Escápula & 13 & 1 & 0,5 & 25 & 2 & 1 & 0,5 & 33,3 & 11 & 3 & 1,5 & 52,3 \\
\hline Húmero: proximal & o & o & o & o & 2 & 1 & 0,5 & 33,3 & 5 & 2 & 1 & 34,8 \\
\hline Húmero: diáfisis & 1 & 1 & 0,5 & 25 & 4 & 2 & 1 & 66,7 & 12 & 2 & 1 & 34,8 \\
\hline Húmero: distal & 3 & 2 & 1 & 50 & 1 & 1 & 0,5 & 33,3 & 2 & 1 & 0,5 & 17,4 \\
\hline Radio-cúbito: proximal & 1 & 1 & 0,5 & 25 & 3 & 2 & 1 & 66,7 & 4 & 2 & 1 & 34,8 \\
\hline Radio-cúbito: diáfisis & 5 & 3 & 1,5 & 75 & 2 & 1 & 0,5 & 33,3 & 8 & 2 & 1 & 34,8 \\
\hline Radio-cúbito: distal & 1 & 1 & 0,5 & 25 & o & $\mathrm{o}$ & o & $\mathrm{o}$ & 2 & 1 & 0,5 & 17,4 \\
\hline Carpianos & 2 & 2 & 0,1 & 7,1 & 5 & 4 & 0,57 & 38,1 & 10 & 3 & 0,21 & 7,3 \\
\hline Innominado & 3 & 1 & 0,5 & 25 & 1 & 1 & 0,5 & 33,3 & 3 & 1 & 0,5 & 17,4 \\
\hline Fémur: proximal & 1 & 1 & 0,5 & 25 & 2 & 1 & 0,5 & 33,3 & 4 & 2 & 1 & 34,8 \\
\hline Fémur: diáfisis & 3 & 1 & 0,5 & 25 & 6 & 1 & 0,5 & 33,3 & 10 & 2 & 1 & 34,8 \\
\hline Fémur: distal & 1 & 1 & 0,5 & 25 & 1 & 1 & 0,5 & 33,3 & 1 & 1 & 0,5 & 17,4 \\
\hline Rótula & 4 & 4 & 2 & 100 & 3 & 3 & 1,5 & 100 & o & $\mathrm{o}$ & $\mathrm{o}$ & o \\
\hline Tibia: proximal & 4 & 2 & 1 & 50 & 2 & 2 & 1 & 66,7 & 9 & 4 & 2 & 69,67 \\
\hline Tibia: diáfisis & 4 & 2 & 1 & 50 & 4 & 1 & 0,5 & 33,3 & 12 & 2 & 1 & 34,8 \\
\hline Tibia: distal & o & o & o & o & 1 & 1 & 0,5 & 33,3 & 7 & 2 & 1 & 34,8 \\
\hline Otros Tarsianos & 5 & 5 & 0,5 & 25 & 2 & 1 & 0,1 & 6,7 & 6 & 6 & 0,6 & 20,9 \\
\hline Astrágalo & 2 & 2 & 1 & 50 & 1 & 1 & 0,5 & 33,3 & 1 & 1 & 0,5 & 17,4 \\
\hline Calcáneo & 3 & 3 & 1,5 & 75 & 1 & 1 & 0,5 & 33,3 & o & o & o & o \\
\hline Metapodio: diáfisis & 29 & 4 & 1 & 50 & 43 & 6 & 1,5 & 100 & 52 & 10 & 2,5 & 87,1 \\
\hline Metapodio: distal & 4 & 1 & 0,2 & 12,5 & 6 & 3 & 0,75 & 50 & 10 & 4 & 1 & 34,8 \\
\hline Falange $1^{\circ}$ & 12 & 5 & 0,6 & 31,2 & 15 & 7 & 0,88 & 58,3 & 53 & 23 & 2,87 & 100 \\
\hline Falange $2^{\circ}$ & 2 & 2 & 0,2 & 12,5 & 9 & 7 & 0,88 & 58,3 & 25 & 13 & 1,62 & 56,4 \\
\hline Falange $3^{0}$ & 3 & 3 & 0,4 & 18,7 & 2 & 2 & 0,25 & 16,7 & 4 & 2 & 0,25 & 8,7 \\
\hline Sesamoideos & 6 & 6 & 0,4 & 18,7 & $\mathrm{o}$ & o & o & $\mathrm{o}$ & 1 & 1 & 0,5 & 17,4 \\
\hline Total & 112 & 54 & & & 118 & 51 & & & 252 & 93 & & \\
\hline
\end{tabular}

Tabla 4. Frecuencia de NISP, MNE, MAU y MAU\% del esqueleto apendicular de Lama guanicoe en el Período III, IV y V de Casa de Piedra de Ortega.

por lo tanto, la densidad mineral ósea no es una variable relevante y/o no explica la conservación diferencial del conjunto. Por último, se observó una correlación no significativa y positiva entre los valores del índice de MGUI para Lama guanicoe y el MAU\% (coeficiente de correlación de Pearson = 0,1880; $p>0,05$ ), lo que sugiere que los perfiles de partes esqueletales no parecen estar determinados por decisiones de transporte selectivo.

Se detectó que el 11,6\% del NISP del Período IV presenta huellas antrópicas (Figura 3). Sólo 0,4\% está afectado por agentes naturales (Tabla 5). El 60\% de los especímenes identificados no presentan termoalteración mientras que el 63,3\% de NID exhiben diferentes grados de termoalteración. El análisis de las huellas de corte indicó que la finalidad predominante se relaciona con el descarne. La fractura transversal es la más frecuente en el conjunto identificado (Tabla 5). La forma del borde más representativa es la de tipo astillado. Un 31,4\% corresponde a fracturas realizadas en huesos en estado fresco, registradas en Lama guanicoe, Rhea pennata y Lycalopex culpaeus. Observamos que Lama guanicoe fue la principal fuente de alimento. Según la disposición de las modificaciones antrópicas identificadas y analizadas, podemos afirmar que tanto los miembros anteriores como los posteriores de este taxón ingresaron al sitio por actividad 
A)

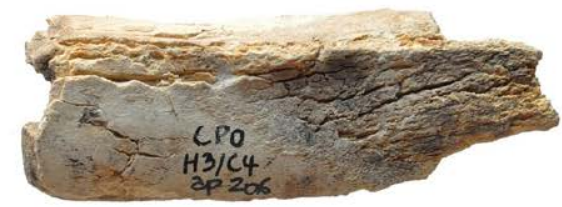

C)

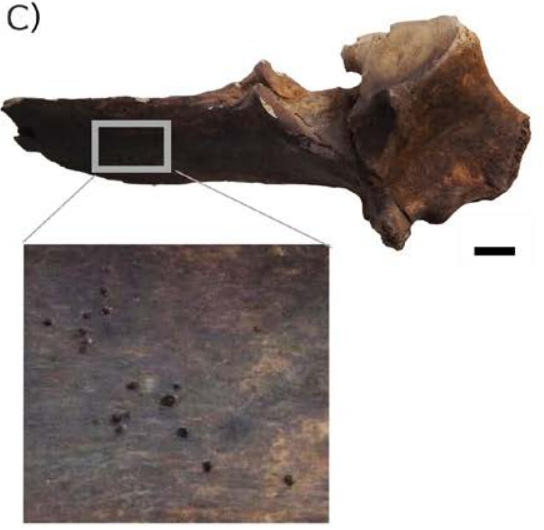

E)

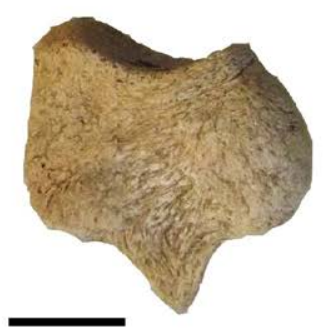

G)

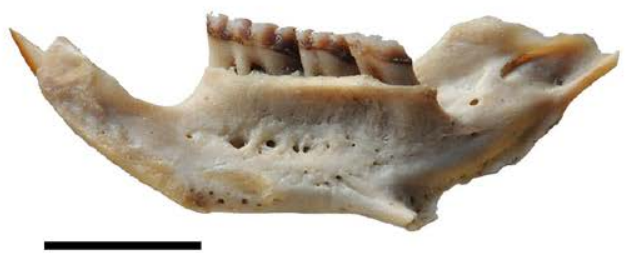

B)

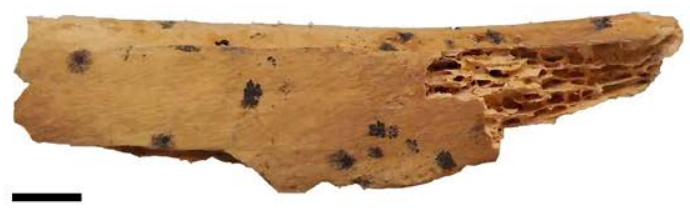

D)

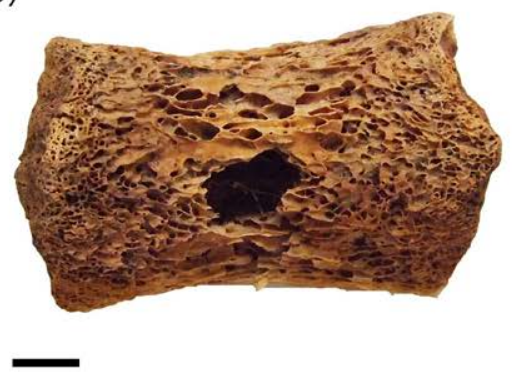

F)

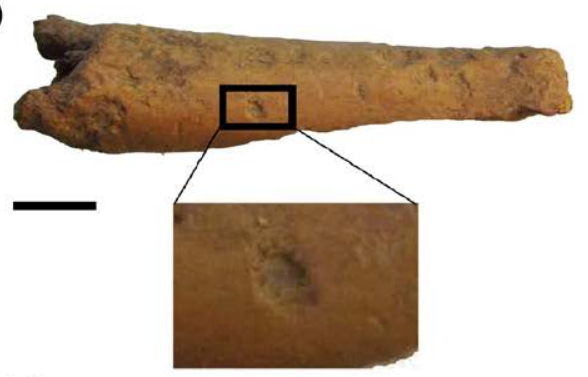

H)

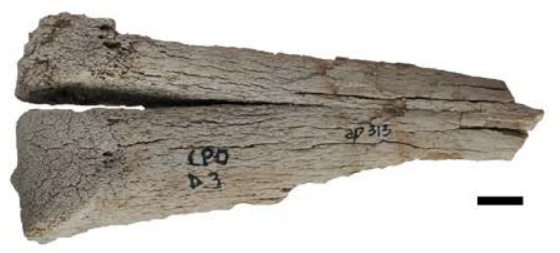

Figura 2. Ejemplos de modificaciones óseas naturales identificadas en Casa de Piedra de Ortega. Período III: A) diáfisis de tibia de Lama guanicoe con evidencias de meteorización (Estadio 3); B) costilla de Lama guanicoe con impregnaciones por óxido de manganeso; C) vértebra torácica de Lama guanicoe con marcas de carnívoros en espina neural (hoyuelos); D) esternebra de Lama guanicoe con indicios de erosión. Período V; E) maleolar de Ovis aries con indicios de erosión; F) primera falange de Lama guanicoe con marcas de carnívoros (pozos); G) mandíbula de Reithrodon auritus con indicios de corrosión digestiva en molares; $H$ ) metapodio de Lama guanicoe con indicios de meteorización avanzada (Estadio 4). Escalas = $1 \mathrm{~cm}$.

humana. Estas regiones anatómicas habrían ingresado a la cueva mayoritariamente, mientras que el cráneo, las vértebras y las costillas lo habrían hecho en menor medida. Rhea pennata, Lycalopex griseus, Lycalopex culpaeus, Conepatus chinga y Chaetophractus villosus también formaron parte de la alimentación de los grupos humanos de modo complementario. Finalmente, en sólo una tibia correspondiente a Caviomorpha registramos quemado distal. Tan sólo $0,41 \%$ de los especímenes identificados se vio afectado por agentes naturales. No obstante, el registro de un porcentaje moderado de fracturas óseas en estado no fresco podría explicarse por la acción de pisoteo. Se 


\begin{tabular}{|c|c|c|c|c|}
\hline & NISP & MNE & MAU & MAU\% \\
\hline Cráneo: occipital & 3 & 1 & 1 & 50 \\
\hline Cráneo: maxilar & 1 & 1 & 1 & 50 \\
\hline Mandíbula & 2 & 1 & 0,5 & 25 \\
\hline Atlas & 1 & 1 & 1 & 50 \\
\hline Axis & 2 & 2 & 2 & 100 \\
\hline Vértebras cervicales 3-7 & 4 & 4 & 0,8 & 40 \\
\hline Vértebras torácicas 1-12 & 12 & 9 & 0,7 & 30 \\
\hline Vértebras lumbares 1-7 & 5 & 4 & 0,7 & 30 \\
\hline Vértebras indeterminadas & 8 & - & - & - \\
\hline Costillas: proximal & 10 & 10 & 0,4 & 20 \\
\hline Costillas: fragmentos & 14 & 6 & 0,2 & 10 \\
\hline Húmero: diáfisis & 6 & 4 & 2 & 100 \\
\hline Húmero: distal & 2 & 1 & 0,5 & 20 \\
\hline Radio: diáfisis & 1 & 1 & 0,5 & 20 \\
\hline Radio: distal & 2 & 1 & 0,5 & 20 \\
\hline Cúbito: proximal & 1 & 1 & 0,5 & 20 \\
\hline Carpianos & 2 & 2 & 0,1 & 30 \\
\hline Fémur: proximal & 1 & 1 & 0,5 & 20 \\
\hline Fémur: diáfisis & 1 & 1 & 0,5 & 20 \\
\hline Rótula & 1 & 1 & 0,5 & 20 \\
\hline Tibia: proximal & 2 & 2 & 1 & 50 \\
\hline Tibia: diáfisis & 1 & 1 & 0,5 & 20 \\
\hline Tibia: distal & 1 & 1 & 0,5 & 20 \\
\hline Otros tarsianos & 3 & 3 & 0,3 & 10 \\
\hline Astrágalo & 1 & 1 & 0,5 & 25 \\
\hline Calcáneo & 1 & 1 & 0,5 & 25 \\
\hline Metapodio: distal & 1 & 1 & 0,2 & 10 \\
\hline Falange $1^{0}$ & 5 & 5 & 0,6 & 30 \\
\hline Falange $2^{\circ}$ & 1 & 1 & 0,1 & 10 \\
\hline Total & 95 & 68 & & \\
\hline
\end{tabular}

Tabla 6. Frecuencia de NISP, MNE, MAU y MAU\% del esqueleto axial y apendicular de Ovis aries en el Período V en Casa de Piedra de Ortega.

registraron marcas de carnívoros (hoyuelos) en un sólo espécimen correspondiente a la diáfisis de húmero de Cetartiodactyla y un sólo fragmento de fémur de Sigmodontinae indeterminado presentó evidencia de corrosión digestiva, de tipo ligera. No se registraron grados elevados de meteorización (Tabla 5).

\section{Período $V$}

Se identificaron 1.026 restos (NISP), mientras que 1.087 se asignaron a NID (Tabla 2). Las cáscaras de huevo de Rhea sp. suman 1.394 restos sin evidencia de termoalteración. Los taxones autóctonos están representados mayoritariamente (Tabla 2). De esta 

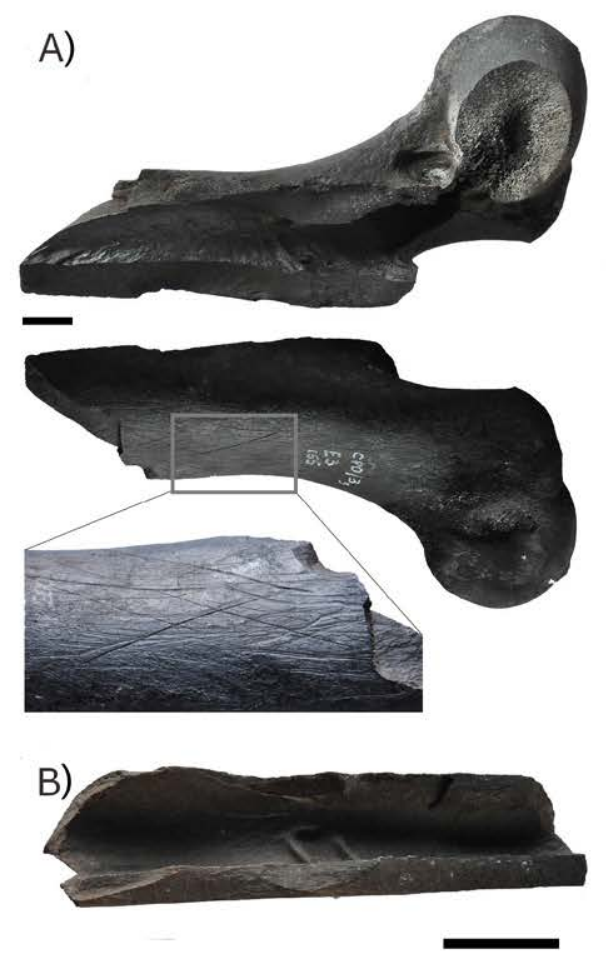

C)
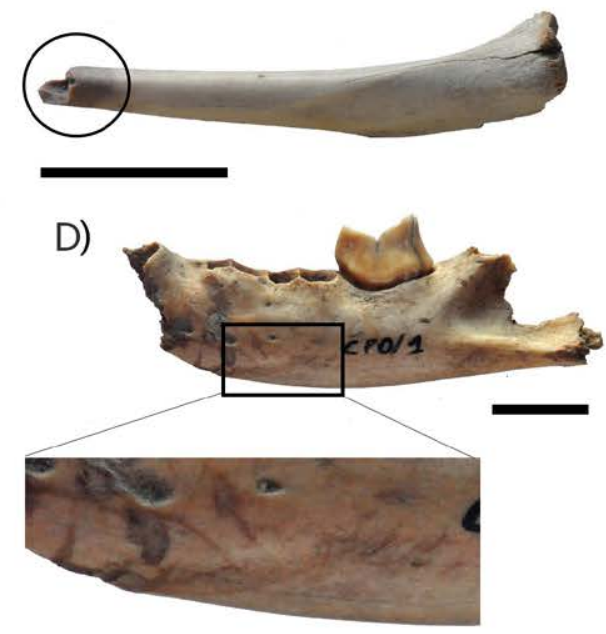

E)

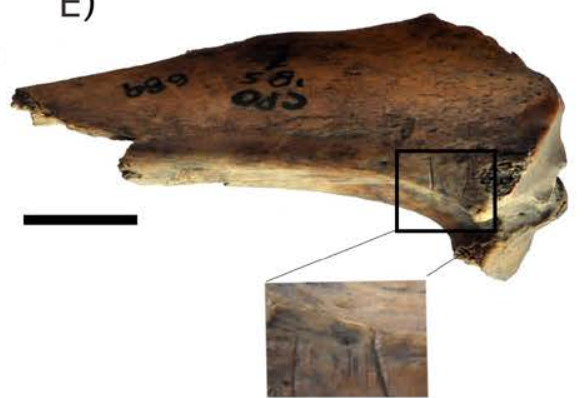

F)

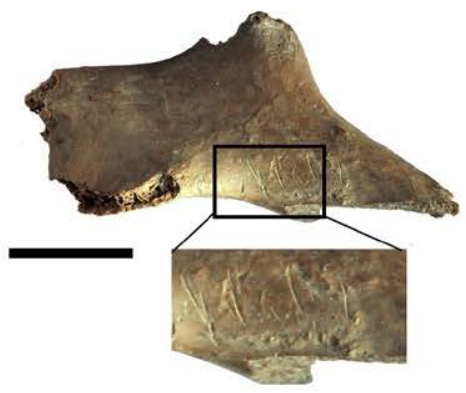

G)

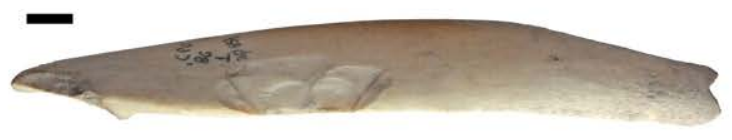

H)

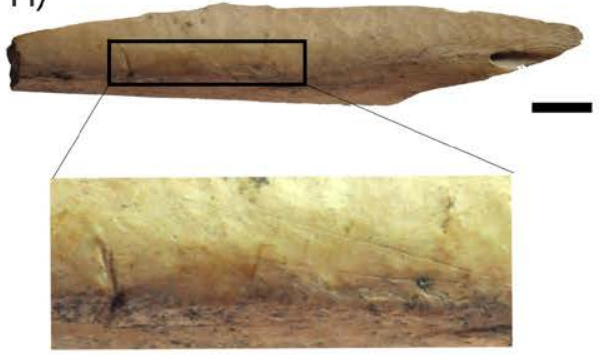

I)

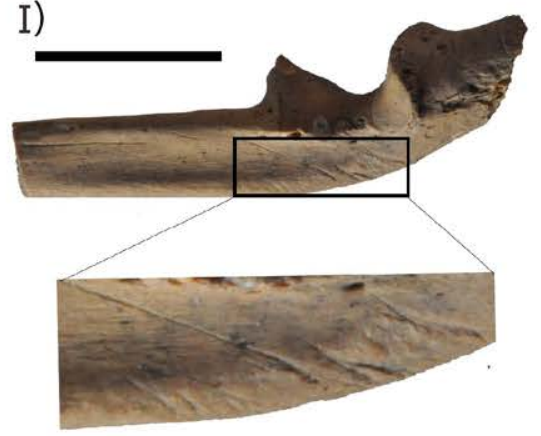

J)

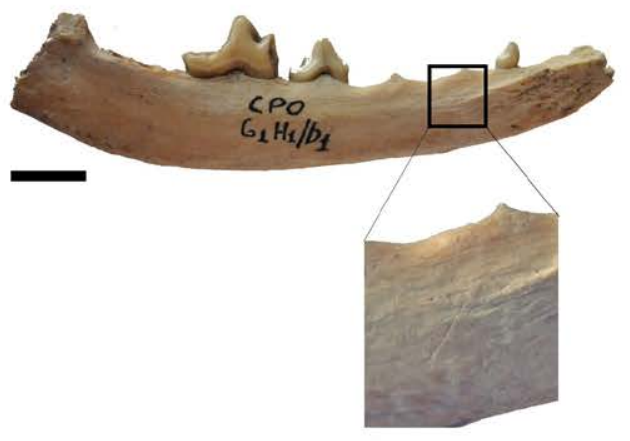

Figura 3. Ejemplos de modificaciones óseas antrópicas registradas en Casa de Piedra de Ortega. Período IV: A) diáfisis distal de húmero de Lama guanicoe con huellas de corte y fractura longitudinal fresca; $B$ ) diáfisis de tibia de Lycalopex culpaeus con negativos de impacto; C) tibia de Caviomorpha con quemado distal. Período V; D) mandíbula de Leopardus sp. con huellas de corte; E) tibia proximal de Lycalopex culpaeus con huellas de corte; F) diáfisis de fémur de Chaetophractus villosus con huellas de corte; $G$ ) borde radio-cúbito de Lama guanicoe con negativos de impacto y fractura longitudinal fresca; $H$ ) diáfisis de tibiotarso de Rhea pennata con huellas de corte y fractura longitudinal fresca; I) cúbito proximal de Conepatus chinga con huellas de corte; J) mandíbula de L. griseus con huellas de corte. Escalas $=1 \mathrm{~cm}$. 
manera, gran parte de los restos identificados se asignaron a Lama guanicoe (NISP\% $=46,9)$ (Tabla 2). Le sigue Chaetophractus villosus con un 12,9\%. Diplodon chilensis y Rhea pennata alcanzan un valor similar, 6,8\% y 5,6\%, respectivamente. Otros taxones como Puma concolor, Lycalopex griseus, Lycalopex culpaeus, Leopardus sp., Conepatus chinga y Zaedyus pichiy tuvieron una representación minoritaria. Los caviomorfos Galea leucoblephara, Microcavia australis y Ctenomys sp. se identificaron en valores bajos ( $\ 3 \%$ ). Con porcentajes menores se hallaron los sigmodontinos Reithrodon auritus y Eligmodontia sp. y el marsupial Thylamys pallidior. Dentro de los taxones exóticos, Ovis aries alcanza la mayor frecuencia de NISP, seguido por Bos taurus y Equus caballus (Tabla 2). Asimismo, se registró un elemento asignado a un lepórido exótico silvestre (cf. Lepus europaeus [liebre europea] / Oryctolagus cuniculus [conejo común]). El cálculo de MNI (Tabla 1) para cada taxón identificado indicó que Microcavia australis es el taxón más abundante, seguido por Conepatus chinga, Galea leucoblephara y Ctenomys sp. Lama guanicoe está representado en baja proporción de MNI. El resto de los taxones exhiben entre un 2 y $6 \%$ del MNI.

El esqueleto apendicular de Lama guanicoe está constituido en un 57,3\% (Tabla 3). La mayoría de los elementos están presentes, a excepción del atlas, axis, vértebras caudales, esternón, rótula y calcáneo. Los especímenes más abundantes son la primera falange y la diáfisis de metapodio. También se identificaron diferentes zonas diagnósticas pertenecientes a escápula, huesos largos, carpales, pelvis y tarsales (Tabla 4). El esqueleto axial de Lama guanicoe comprende principalmente fragmentos de molares (Tabla 3). Según la fusión de los elementos óseos de Lama guanicoe se reconoció 1 individuo juvenil y 4 individuos adultos en el Período V. Se observó que la primera falange es el elemento anatómico más abundante. Los metapodios, la tibia y la segunda falange oscilan entre el 50 y $80 \%$ (Tabla 3 y 4 ). El resto del conjunto comprende valores moderados-bajos de hasta un $30 \%$. Observamos que para Ovis aries el esqueleto axial está representado en un 65,3\% mientras que el esqueleto apendicular alcanza un 34,7\%. Se encontraron la mayoría de los elementos anatómicos, a excepción de las vértebras caudales, sacro, pelvis, esternón, escápula, tercera falange y sesamoideos (Tabla 6). Los especímenes que cuentan con mayor frecuencia de NISP son las vértebras torácicas y las costillas. Los resultados de los cálculos de MAU\% para Ovis aries indican que el axis y el húmero son los elementos anatómicos más abundantes. La mayor parte de los elementos tiene una abundancia entre el 50 y $25 \%$. Se observó una correlación moderada y no significativa entre los valores de MAU\% y el índice de densidad ósea de Lama guanicoe (rho de Spearman $=0,403 ; \mathrm{p}>0,05$ ), lo que sugiere que la densidad mineral ósea no es una variable relevante y/o no explica la conservación diferencial del conjunto. Se observó una correlación no significativa entre los valores de MAU\% y el índice de utilidad de la carne de Lama guanicoe (coeficiente de correlación de Pearson $=0,0420 ; \mathrm{p}>0,05$ ), lo que sugiere que el conjunto no está afectado mayormente por el transporte selectivo de partes esqueletales. En el caso de la correlación de valores para Ovis aries, observamos una asociación no significativa y negativa (coeficiente de correlación de Pearson = -0,0968; $p>0,05$ ), lo que sugiere que el conjunto tampoco está afectado por el transporte selectivo de partes esqueletales.

Las huellas de corte son las modificaciones antrópicas más frecuentes tanto en los taxones autóctonos como exóticos (Tabla 5 y Figura 4). La actividad predominante está relacionada con el descarne. Hay baja incidencia de modificaciones óseas producto de la acción de agentes naturales (Tabla 5 y Figura 2). No obstante, no descartamos que el registro de fracturas óseas en estado no fresco pueda explicarse por la acción de pisoteo. Se registraron marcas de carnívoros (hoyuelos) en un bajo porcentaje de especímenes pertenecientes a la primera y segunda falange y en fragmentos de costilla de Lama guanicoe. No se encontraron restos con grados elevados de meteorización, presentando la mayor parte del conjunto ausencia de exfoliaciones, fisuras, grietas y descascaramiento. Se detectó evidencia de erosión en especímenes correspondientes a 


\begin{tabular}{|c|c|c|c|c|c|c|c|}
\hline & & \multicolumn{2}{|c|}{ Período III } & \multicolumn{2}{|c|}{ Período IV } & \multicolumn{2}{|c|}{ Período V } \\
\hline & & NISP & NID & NISP & NID & NISP & NID \\
\hline \multirow{9}{*}{$\begin{array}{l}\text { Modificaciones } \\
\text { antrópicas }\end{array}$} & Huellas de corte total & 33 & - & 51 & - & 151 & - \\
\hline & a. Descarnado & 15 & - & 26 & - & 98 & - \\
\hline & b. Desarticulación & 5 & - & 12 & - & 22 & - \\
\hline & d. Cuereado & 2 & - & 10 & - & 18 & - \\
\hline & e. Finalidad no determinada & 11 & - & 3 & - & 13 & - \\
\hline & Raspado & 1 & - & & - & 3 & - \\
\hline & Negativo de impacto & 1 & - & 3 & - & 5 & - \\
\hline & Machacado & - & - & 2 & - & 8 & - \\
\hline & Total & 35 & - & 56 & - & 167 & - \\
\hline \multirow{5}{*}{ Otras modificaciones } & Piqueteado y hoyuelos - pits & 2 & - & 1 & - & 3 & - \\
\hline & Sustancias adheridas (manganeso) & 4 & - & - & - & - & - \\
\hline & Erosión & 3 & - & - & - & 14 & - \\
\hline & Corrosión digestiva & - & - & 1 & - & 2 & - \\
\hline & Total & 9 & - & 2 & - & 19 & - \\
\hline \multirow{6}{*}{ Alteración térmica } & No quemado & 251 & 288 & 313 & 377 & 836 & 491 \\
\hline & Quemado incipiente & 39 & 166 & 28 & 85 & 86 & 201 \\
\hline & Quemado avanzado & 35 & 109 & 62 & 157 & 65 & 227 \\
\hline & Carbonizado & 38 & 70 & 56 & 107 & 26 & 86 \\
\hline & Calcinado & 22 & 247 & 25 & 205 & 13 & 82 \\
\hline & Total & 385 & 880 & 484 & 931 & 1.026 & 1.087 \\
\hline \multirow{6}{*}{ Meteorización } & Estadio o & 382 & 877 & 478 & 931 & 986 & 1076 \\
\hline & Estadio 1 & - & - & 4 & - & 23 & 5 \\
\hline & Estadio 2 & 2 & 3 & - & - & 13 & 6 \\
\hline & Estadio 3 & 1 & - & - & - & 3 & - \\
\hline & Estadio 4 & - & & 2 & - & 1 & - \\
\hline & Total & 385 & 880 & 484 & 931 & 1.026 & 1.087 \\
\hline \multirow{4}{*}{ Fractura } & Espiral & 31 & - & 22 & - & 51 & - \\
\hline & Longitudinal & 72 & - & 129 & - & 256 & - \\
\hline & Transversal & 131 & - & 167 & - & 411 & - \\
\hline & Total & 234 & - & 318 & - & 718 & - \\
\hline \multirow{3}{*}{ Borde } & Regular & 79 & - & 99 & - & 207 & - \\
\hline & Astillado & 155 & - & 219 & - & 511 & - \\
\hline & Total & 234 & - & 318 & - & 718 & - \\
\hline
\end{tabular}

Tabla 6. Frecuencia de NISP, MNE, MAU y MAU\% del esqueleto axial y apendicular de Ovis aries en el Período V en Casa de Piedra de Ortega.

R.pennata, Mammalia indeterminado (mediano-pequeño), Ovis aries, Lama guanicoe y Lycalopex griseus. La mayor parte del conjunto identificado no está quemado (Tabla 5). Sin embargo, se registró que el conjunto NID presenta mayor número de especímenes termoalterados. La fractura más representativa en el conjunto identificado es la de tipo transversal (Tabla 5). La mayor cantidad de especímenes cuentan con forma de borde astillado. El 70\% corresponde a fracturas realizadas sobre huesos en estado fresco, 

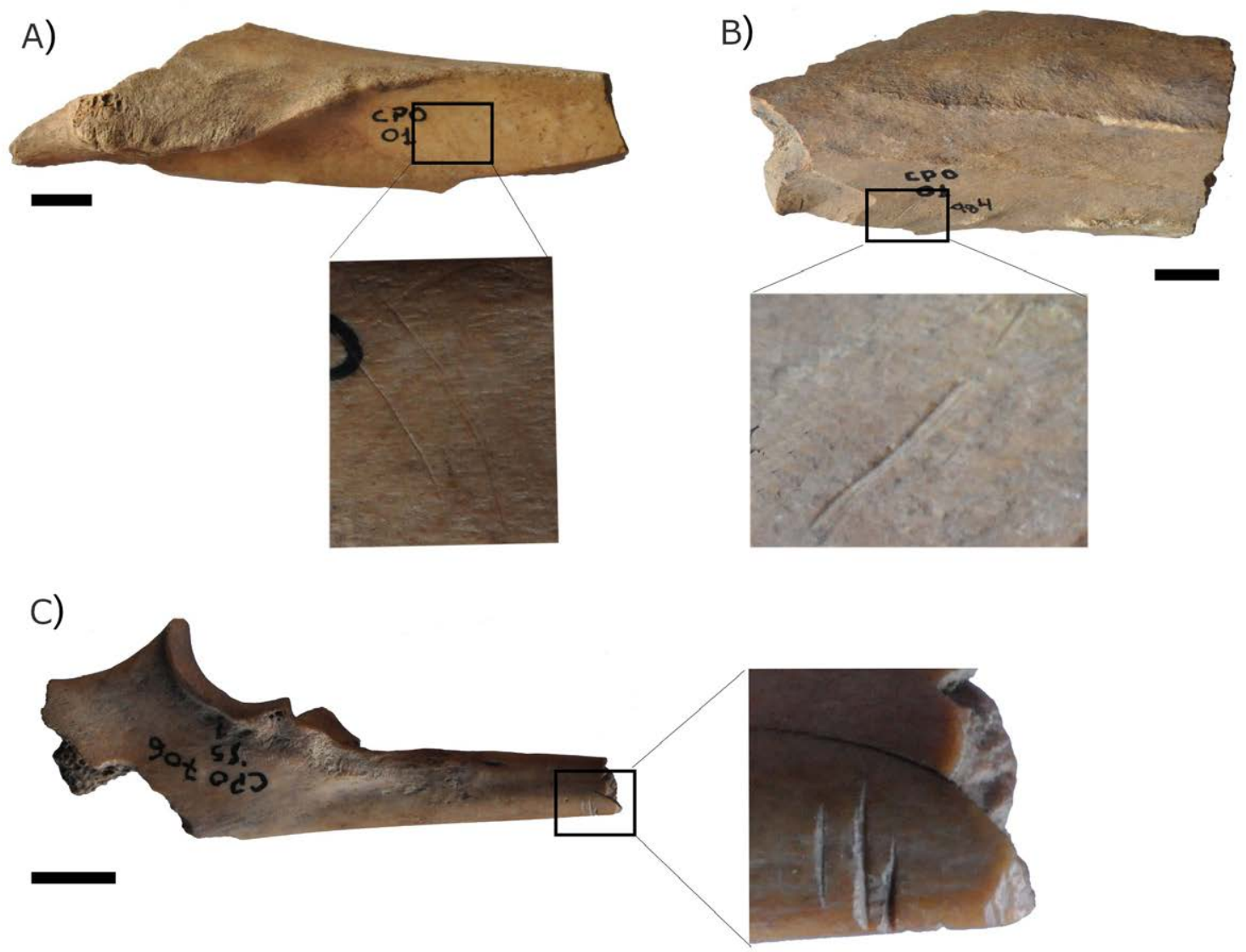

Figura 4. Ejemplos de modificaciones óseas antrópicas registradas en taxones exóticos en el Período V de Casa de Piedra de Ortega. A) fémur de Equus caballus con huellas de corte y fractura longitudinal fresca; B) tibia de Bos taurus con huellas de corte; C) cúbito de Ovis aries con huellas de corte. Escalas $=1 \mathrm{~cm}$.

identificadas en restos de Rhea pennata, Mammalia indeterminado grande, Mammalia indeterminado mediano-grande, Bos taurus, Ovis aries, Lama guanicoe, Equus caballus, Puma concolor, Lycalopex griseus y Leopardus sp.

\section{Discusión}

Lama guanicoe ocupó un lugar importante en la subsistencia de los grupos humanos que habitaron $\mathrm{CPO}$ en momentos previos y posteriores al contacto hispano-indígena. Sin embargo, su explotación como recurso principal se complementó con la utilización de otros taxones.

Entre las especies que ingresaron al sitio por la acción de agentes naturales se encuentran piches, roedores y marsupiales. También se encontraron restos de otros taxones (por ejemplo, guanacos) con evidencias de modificaciones naturales. Si bien no se encontraron modificaciones antrópicas en los restos de Diplodon chilensis presentes en las muestras analizadas en este trabajo, sabemos que dicho taxón se utilizó para la confección de cuentas y adornos personales durante toda la secuencia de ocupación de CPO (Fernández y Ramos, 2009). Pardiñas (1999a, 1999b) y Teta y colaboradores (Teta et al., 2005) señalaron que los micromamíferos presentes en las ocupaciones tempranas de CPO tuvieron un origen mixto, debido a la depredación de aves Strigiformes y al consumo antrópico. Este escenario parece mantenerse en parte a través de la secuencia de CPO, en coincidencia con otros sitios de Norpatagonia (Fernández et al., 2017b). 
En los tres períodos estudiados existió una supremacía de los roedores más grandes, diurnos y de comportamientos sociales (caviomorfos), respecto de aquellos de tamaño chico, nocturnos y solitarios (sigmodontinos). Además, se halló evidencia directa en el Período IV donde se registró un espécimen de caviomorfo con patrón de quemado distal lo que podría indicar su consumo como alimento (Pardiñas, 1999a, 1999b). En el Período IV y V se documentaron dos restos con corrosión digestiva ligera, lo que sugiere la acción de aves Strigiformes (Andrews, 1990; Fernández et al., 2017b). En la zona de estudio encontramos diferentes especies de Strigiformes (Tyto alba, Bubo virginianus magellanicus, Asio flammeus, Athene cunicularia). Estas especies se alimentan sobre todo de micromamíferos, como roedores sigmodontinos, pero sólo Tyto alba y Bubo virginiaunus magellanicus acostumbran utilizar como refugio el interior de cuevas y aleros (Pardiñas, 1999a, 1999b). Tyto alba expone los grados de corrosión digestiva más bajos correspondientes a la categoría ligera (Andrews, 1990), mientras que Bubo virginiaunus magellanicus puede presentar evidencias de digestión moderada (Montalvo, Fernández y Tallade, 2015). En relación con las marcas de carnívoros, su frecuencia es baja en los tres períodos. Se encuentran presentes tanto en el esqueleto apendicular como axial de Lama guanicoe. Los elementos anatómicos que exhiben marcas de carnívoros (vértebras, costillas, pelvis, huesos largos y autopodios) se corresponden con aquellos indicados por la bibliografía especializada (DomínguezRodrigo y Martí Lezama, 1996; Marean, Spencer, Blumenschine y Capaldo, 1992).

A lo largo de los tres períodos se observaron grados bajos de meteorización. Esto nos indica un enterramiento rápido de los conjuntos arqueofaunísticos, potenciado por las cualidades propias de $\mathrm{CPO}$, es decir, que al ser un alero presenta una baja exposición a los agentes meteóricos y mayor acumulación de sedimentos.

En los Períodos III, IV y V, Lama guanicoe es el taxón que presenta mayor frecuencia de NISP y de modificaciones antrópicas. Varios taxones, tanto autóctonos (Rhea pennata, Lycalopex culpaeus, Lycalopex griseus, Leopardus sp., Conepatus chinga, Chaetophractus villosus, Zaedyus pichiy y Caviidae indeterminado) como exóticos (Bos tarurus, Ovis aries y Equus caballus), se incorporaron a la alimentación de los grupos humanos que habitaron $\mathrm{CPO}$ en los tres períodos. Por otra parte, se registra un aumento de la riqueza (NTaxa) a lo largo de los tres períodos y un aumento de la diversidad de especies (índice de Shannon), sobre todo en el Período V (Período III: NTaxa $=3$, Shannon $\mathrm{H}=0$,86; Período IV: NTaxa $=7$, Shannon $\mathrm{H}=0,85$; Período V: NTaxa $=9$, Shannon $\mathrm{H}=2,03)$. Esto sugiere que no hubo un reemplazo de fauna nativa por exótica, pero que la incorporación de la segunda pudo implicar una intensificación en el uso de los recursos faunísticos y, además, un aprovechamiento más equitativo. Muy pocos huesos de Lama guanicoe están completos, tratándose básicamente de carpianos, tarsianos y tercera falange. Los huesos largos de este taxón están fragmentados, junto con las mandíbulas, calcáneo y falanges (primera y segunda), vértebras, costillas y pelvis. Si bien no podemos decir que todas las fracturas fueron por agentes antrópicos, una parte de las mismas pueden interpretarse como intencionales debido a la presencia de marcas de impacto del percutor sobre cara externa y negativos de impacto. Por otro lado, una parte significativa de las fracturas se produjeron cuando los huesos se encontraban aún frescos mientras que otras se produjeron en estado no fresco. Estas últimas suelen presentar borde de tipo astillado y podrían relacionarse con la acción de pisoteo dentro de la cueva. Los patrones intencionales de fractura evidencian el procesamiento de la fauna para su transporte, consumo o utilización como materia prima en diferentes contextos (Mengoni Goñalons, 1999). En los Períodos IV y V hay fragmentos de diáfisis de hueso largo (radio-cúbito y metapodio) de Lama guanicoe y fragmentos de diáfisis de tibia de Lycalopex culpaeus con huellas de negativos de impacto. Estas huellas pueden ser el resultado de la implementación de diversos métodos de fractura, como por ejemplo percutor y yunque, yunque estático y hueso móvil (De Nigris, 2004). También observamos que varios de los huesos fragmentados que poseen 
cavidad medular, como las falanges (primera y segunda), presentan fracturas espirales y longitudinales principalmente. Estos tipos de fracturas podrían estar relacionadas con el aprovechamiento intensivo de los recursos.

En el trozamiento terciario, la dimensión de los huesos depende del modo de preparación de los alimentos, es decir, si van a asarse o deben tener un tamaño adecuado para caber en el recipiente que se usa para hervirlas (Mengoni Goñalons, 1999). En el caso de CPO se encontraron fragmentos de tiestos de cerámica en bajas proporciones (Fernández y Vitores, 2009), por lo que no se espera que el modo principal de preparación haya sido el hervido.

Una porción del conjunto analizado presentó indicios de termoalteración en diferentes grados. Esto se infiere del color de los fragmentos, como así también por la presencia de cuarteaduras producidas por la acción directa o indirecta del fuego (Mengoni Goñalons, 1999). Si bien la coloración de los huesos puede exponer algún problema de equifinalidad debido a las características intrínsecas de su enterramiento (Shipman et al., 1984), consideramos que en CPO no tuvieron lugar condiciones diagenéticas que pudieron alterar la coloración de los especímenes óseos. Esto se debe a que son muy pocos los especímenes que presentan por ejemplo impregnaciones por óxido de manganeso. Los especímenes termoalterados pertenecen principalmente a Lama guanicoe, aunque el resto de los taxones también tienen termoalteraciones. A lo largo de los tres períodos de CPO se observa que los grados de termoalteración más frecuentes son el quemado incipiente, quemado avanzado y carbonizado. La categoría menos frecuente es el calcinado. Los especímenes que presentan grados incipientes y avanzados de quemado podrían indicar una exposición regular a la acción del calor en el proceso de consumo. No obstante, numerosos trabajos señalan que los diferentes grados de termoalteración pueden ser producto de la acción de varios agentes (Álvarez et al., 2017). Los especímenes carbonizados y calcinados podrían informar acerca de las prácticas de descarte y de eliminación de desechos en fogones (De Nigris, 2004). Los fragmentos de cáscaras de huevo de Rhea sp. con indicios de termoalteración podrían relacionarse con la exposición al fuego en el proceso de consumo de los huevos (Salemme y Frontini, 2011).

\section{La fauna exótica doméstica}

La incorporación de Equus caballus, Bos taurus y Ovis aries a la alimentación de los grupos humanos no significó un reemplazo en cuanto con la explotación de especies autóctonas. Lama guanicoe fue el recurso más explotado junto con otros taxones autóctonos según lo indican las modificaciones antrópicas y a las frecuencias relativas y absolutas de los restos óseos. Los tres taxones exóticos domésticos se incorporaron a la alimentación como recursos secundarios, aunque Ovis aries fue el taxón más explotado.

Existen diferencias con relación a la abundancia de partes esqueletarias entre Lama guanicoe y Ovis aries. En este último, se observó un mayor ingreso del cráneo junto con las vértebras y costillas, seguidas por los miembros. Los huesos del sacro, pelvis y vértebras caudales estaban ausentes. Las huellas de procesamiento antrópico se concentraron en la parte superior de los miembros anteriores y en la zona inferior de los miembros posteriores, como así también en la mandíbula, vértebras y costillas. Mientras que para Lama guanicoe se observó una tendencia de ingreso al sitio principalmente de los miembros anteriores y posteriores y luego los elementos del esqueleto axial. Para Ovis aries observamos una tendencia inversa. Sin embargo, encontramos coincidencia en las partes esqueletarias con evidencia de procesamiento antrópico, es decir, principalmente miembros anteriores y posteriores, seguidos de vértebras y costillas. Según las correlaciones entre los valores de MGUI con los valores de MAU\% 
obtenidos para Lama guanicoe y Ovis aries, en ninguno de los dos casos se verificó un transporte selectivo de partes esqueletarias.

La distribución similar de las huellas de corte entre restos de Lama guanicoe y Ovis aries, con índice alto y bajo de carne, sugiere un procesamiento intensivo de las partes nutritivas que ofrecen ambas presas. Además, la ubicación de las huellas en la topografía de los elementos anatómicos y la finalidad inferida sugieren que están representadas todas las etapas del despostamiento. Las huellas se produjeron por artefactos líticos y no por artefactos metálicos. Estas presentan los rasgos morfológicos utilizados para caracterizar este tipo de modificaciones óseas (Fernández-Jalvo y Andrews, 2016), es decir, se trata de incisiones de lados paralelos, de ancho y largo variable, como así también de profundidad no uniforme, junto con una sección transversal en $\mathrm{V}$ y estrías paralelas. Por último, existe una clara asociación entre los conjuntos arqueofaunísticos y los artefactos y desechos líticos (Fernández, M., 2001).

Las crónicas tempranas de viajeros mencionan la utilización de caballos como medio de transporte entre los indígenas en la zonas cercanas al área de estudio (Cabrera, [1625] 2000, pp. 110,114; Cox, 1863, pp. 162, 169; Menéndez, [1791-1794] 1896; Musters, [1871] 1964, p. 130; Vignati, 1964, p. 497). También se describe la utilización de caballos como bien de comercio (Villarino, [1782-1783] 1972, p. 990) y para la confección de subproductos y su posterior intercambio, por ejemplo, monturas y obtención de cueros para la preparación de toldos (Furlong, 1943, p. 26; Menéndez, [1791-1794] 1896, p. 303). Alguno viajeros detallan su uso como alimento y reparto de la presa (Cox, 1863, p. 152; Musters, [1871] 1964, p. 134). Por último, las fuentes aportan datos sobre la inclusión de caballos en enterramientos humanos y rituales indígenas (Claraz, [1865-1866] 1988, p. 80; Furlong, 1943, p. 129; Havestadt, 1930, pp. 228-229; Villarino, [1782-1783] 1972, p. 1069) junto con la importancia de este animal en la cosmovisión indígena (Menéndez, [1791-1794] 1896, p. 62). Se menciona que Bos taurus se utilizó principalmente como alimento, bien de comercio o de intercambio entre los grupos de indígenas y entre estos y los españoles (Rosales, 1877; Viedma, [1779] 1938, pp. 1-26) y para la obtención de subproductos, como la realización de canastas hechas con las ubres de las vacas (Cox, 1863, p. 144), la utilización de los cueros para la realización de toldos (Furlong, 1943, p. 90) y corazas (Vignati, 1931, p. 37)(Furlong 1943). En relación con Ovis aries, se menciona su uso como alimento y el uso de cueros para confeccionar camas (Cox, 1863, p. 140; Menéndez, [1791-1794] 1896, p. 218).

La información proveniente de fuentes documentales nos permitió contextualizar el análisis de los conjuntos arqueofaunísticos de CPO. A pesar de que entre las crónicas existen diferencias en la forma en que se presenta la información relacionada con la utilización de Equus caballus, Bos taurus y Ovis aries tanto como alimento, medio de locomoción o como materia prima para la obtención de subproductos, en distintos momentos y en diferentes lugares del noroeste de Patagonia, es posible identificar una tendencia en el uso de estos taxones exóticos domésticos por parte de los grupos humanos de la zona de estudio.

En este sentido, si bien muchos viajeros describen un extenso uso de la fauna exótica doméstica en la vida de los grupos humanos del área, observamos que el registro arqueológico de CPO no indica que la fauna exótica haya impactado de modo considerable en la subsistencia de los grupos humanos.

\section{Comparación con otros sitios del área de estudio}

El estudio realizado en el sitio arqueológico Valle Encantado I (Hajduk y Albornoz, 1999) indicó que, al igual que en CPO, durante las ocupaciones pre y posthispánicas la subsistencia estuvo basada en Lama guanicoe y que fue complementada con la 
explotación de otros taxones de porte menor. Asimismo, la explotación de Equus caballus, Bos taurus y Ovis aries no implicó un reemplazo de los taxones autóctonos, sino una complementariedad en la utilización de recursos faunísticos. En Valle Encantado 1 se sucedieron ocupaciones temporarias de tipo "paradero", con actividades vinculadas al procesamiento y consumo de alimentos derivados de la caza, la pesca y la recolección, junto con un aprovechamiento del ganado. Además, Hajduk interpreta que los habitantes de Valle Encantado 1 ya eran cazadores ecuestres (Hajduk y Albornoz, 1999).

El análisis del sitio arqueológico La Marcelina 1 (Silveira y Cordero, 2014) sugirió que Lama guanicoe fue el taxón más explotado a lo largo de las ocupaciones, mientras que los mamíferos medianos cumplieron un papel complementario en la alimentación. Congruentemente con $\mathrm{CPO}$, se observó un ingreso mayoritario de las mismas partes esqueletarias de Lama guanicoe. Esto nos puede informar sobre una práctica de trozamiento compartida por los habitantes de CPO y La Marcelina 1. En ninguno de los dos sitios existió un reemplazo en la explotación de taxones autóctonos por exóticos. Lama guanicoe siguió siendo el recurso más explotado, en tanto Equus caballus, Bos taurus, Ovis aries y los mamíferos medianos cumplieron un papel complementario en la alimentación.

\section{Conclusión}

La baja incidencia de indicios de meteorización y de erosión y la ausencia de evidencias de transporte (como agentes hídricos y eólicos) en los tres períodos de CPO, indican una buena conservación y un enterramiento rápido de los conjuntos arqueofaunísticos, potenciado por el hecho de que CPO se encuentra al reparo de los agentes meteóricos. Sin embargo, no se descarta la presencia de actividades de pisoteo evidenciadas por las fracturas en especímenes en estado seco y por la capa de guano consolidado en el Período V.

En los tres períodos de $\mathrm{CPO}$ se registró una baja frecuencia de especímenes óseos con marcas de acción de carnívoros. Por otra parte, se observaron restos de sigmodontinos con evidencia de corrosión digestiva ligera, sugiriendo su ingreso por la acción de aves Strigiformes, posiblemente Tyto alba.

La gran mayoría de los restos arqueofaunísticos se depositaron por actividades humanas, que incluyeron la explotación de fauna autóctona y exótica para alimentación y uso de las pieles. Lama guanicoe, Rhea pennata y Conepatus chinga se explotaron sostenidamente a lo largo de los tres períodos de CPO, siendo Lama guanicoe el principal recurso. Durante el Período IV, Lycalopex griseus, Lycalopex culpaeus y Chaetophractus villosus se incorporaron a la dieta. En el Período V, se agregan taxones exóticos domésticos como Equus caballus, Bos taurus y Ovis aries. En tanto, se plantea que no hubo un reemplazo de la explotación de la fauna autóctona con la llegada de la fauna exótica doméstica. Esta última se incorporó a la dieta de los habitantes de CPO de modo complementario. En este sentido, en los períodos posthispánicos se observó un aumento en la intensidad de explotación de Lama guanicoe, como así también una diversificación taxonómica, evidenciada en la explotación de nuevos taxones, no utilizados en el último período posthispánico.

La especie exótica más explotada fue Ovis aries. La comparación con el aprovechamiento de Lama guanicoe señaló similitudes y diferencias: 1) el ingreso al sitio de las partes esqueletales fue distinto ya que en Lama guanicoe predominaron los miembros y luego cráneo y costillas, mientras que para Ovis aries se observó una tendencia contraria;2) el transporte selectivo de partes esqueletales no afectó la abundancia de los elementos 
anatómicos para ninguno de los dos taxones; 3) la frecuencia de huellas de corte fue mayor en Ovis aries; 4) la ubicación de las mismas en los elementos anatómicos fue similar en ambos taxones; 5) hubo un procesamiento intensivo de las dos presas; 6) la principal finalidad de las huellas de corte en ambos taxones se relacionó con la extracción de carne; 7) tanto en Lama guanicoe como en Ovis aries estuvieron representadas todas las etapas del despostamiento, desde el desposte primario hasta la de consumo final.

Bos taurus y Equus caballus se utilizaron como alimento, pero en menor medida que Ovis aries. Las fuentes documentales y el registro arqueofaunístico de CPO sugieren que Equus caballus, Bos taurus y Ovis aries recibieron usos diferentes. Sin embargo, el uso extensivo señalado en los relatos de los viajeros no está reflejado en CPO ni en otros sitios arqueológicos del área de estudio, ya que los resultados no indican un impacto sustancial de los taxones exóticos domésticos en la subsistencia.

Finalmente, es necesario ampliar la información proveniente de los estudios arqueológicos del sector noroeste de Patagonia para alcanzar un panorama más claro del impacto de la fauna exótica doméstica en la subsistencia de los grupos humanos.

\section{Agradecimientos}

Este trabajo se realizó en el marco de los proyectos UbaCyT (2014-2017), CONICET (PIP-0244), Consejo Superior de Investigaciones Científicas de Cooperación Internacional (i-COOPB-20287) y UNLP (11/N851). Agradecemos a Eduardo Crivelli Montero, Mabel Fernández, Marcelo Vitores, Matilde Lanza, Mariana De Nigris y Pablo Fernández por los comentarios y sugerencias realizados. También agradecemos a los evaluadores anónimos que contribuyeron a mejorar el manuscrito. 


\section{Q Referencias citadas}

"Albornoz, A. y Hajduk, A. (2009). "Ladran Sancho I". Jinetes y caballos en el arte rupestre en la arqueología y la etnohistoria del área del Nahuel Huapi. Trabajo Presentado en las XII Jornadas Interescuelas. San Carlos de Bariloche, Argentina.

» Álvarez, M. C., Massigoge, A., Scheifler, N., González, M., Kaufmann, C., Gutiérrez, M. y Rafuse, D. (2017). Taphonomic Effects of a Grassland Fire on a Modern Faunal Sample and its Implications for the Archaeological Record. Journal of Taphonomy, 15, 77-90.

»Andrews, P. (1990). Owls, Caves and Fossils. Chicago: University of Chicago Press.

» Beherensmeyer, A. (1978). Taphonomic and ecologic information from bone weathering. Paleobiology, 4, 150-162.

» Binford, L. (1978). Nunamiut Ethnoarchaeology. Nueva York: Academic Press.

》 Binford, L. (1981). Bones: Ancient Men and Modern Myths. Nueva York: Academic Press.

»Blumenshine, R., Marean, C. y Capaldo, S. (1996). Blind tests of inter-analyst correspondence and accuracy in the identification of cut marks, percussion marks, and carnivore tooth marks. Journal of Archaeological Science, 43, 493-507.

"Borrero, L. (1981). La economía prehistórica de los pobladores del Alero de los Sauces (Neuquén, Argentina). En A. Sanguinetti de Bórmida (Ed.), Prehistoria de la cuenca del Río Limay. 1a parte: Los aleros del Limay norte (Área de El Chocón) (pp. 111-124). Buenos Aires: Universidad de Buenos Aires, Facultad de Filosofía y Letras.

»Borrero, L. (1990). Taphonomy of guanaco bones in Tierra del Fuego. Quaternary Research, 34, 361-371.

» Borrero, L. (1995). Arqueología de la Patagonia. Palimpsesto, 4, 9-55.

»Cabrera, G. [1625] (2000). Relaciones de la Jornada a los Césares (1625). Buenos Aires: Amerindia.

»Claraz, J. [1865-1866] (1988). Diario de viaje de exploración al Chubut. 1865-1866. Buenos Aires: Marymar.

" Cordero, J. A. (2009). Arqueofauna de las primeras ocupaciones de cueva Epullán Grande. Cuadernos de Antropología, 5, 159-188.

" Cordero, J. A. (2011). Arqueozoología del alero Carriqueo, Depto. de Pilcaniyeu, Río Negro. Sociedades de Paisajes Áridos y Semiáridos, IV(b), 63-79.

" Cordero, J. A. (2012). Las prácticas de subsistencia de las sociedades cazadorasrecolectoras del noroeste de la Patagonia argentina a lo largo del Holoceno. Archaeofauna. International Journal of Archaeozoology, 21, 99-120.

»Costamagno, S., Théry-Parisot, I., Brugal, J. P. y Guibert, R. (2005). Taphonomic consequences of the use of bones as fuel: experimental data and archaeological consequences. En T. O'Connor (Ed.), Biosphere to Lithosphere. New Studies in Vertebrate Taphonomy (pp. 51-62). Oxford: Oxbow Books.

" Cox, G. (1863). Viaje a las rejiones septentrionales de la Patagonia. Santiago: Imprenta Nacional.

»Crivelli, E. y Fernández, M. (2010). El paisaje arqueológico de Paso Flores, Provincia de Río Negro, Argentina. Cuadernos de Antropología, 5, 125-158. 
»De Nigris, M. (2004). El consumo en grupos cazadores recolectores: un ejemplo zooarqueológico de Patagonia Meridional. Buenos Aires: Sociedad Argentina de Antropología.

» Domínguez-Rodrigo, M. y Martí Lezama, R. (1996). Un estudio etnoarqueológico de un campamento temporal Ndorobo (Maasai) en Kulalu (Kenia). Trabajos de Prehistoria, 53 , 131-143.

» Elkin, D. (1995). Volume Density of South American Camelid Skeletal Parts. International Journal of Osteoarchaeology, 5(1), 29-37.

» Fernández, F., del Papa, L., Mange, E., Teta, P., Crivelli Montero, E. y Pardiñas, U. (2016). Human subsistence and environmental stability during the last 2200 years in Epullán Chica cave (northwestern Patagonia, Argentina): A perspective from the zooarchaeological record. Quaternary International, 391, 38-50.

» Fernández, F., Teta, P. y Pardiñas, U. (2017a). Evidencias arqueológicas de explotación antrópica de micromamíferos en el extremo austral de América del Sur. Anales de Arqueología y Etnología, 72, 9-32.

» Fernández, F., Montalvo, C., Fernández-Jalvo, Y., Andrews, P. y López, J. M. (2017b). A re-evaluation of the taphonomic methodology for the study of small mammal fossil assemblages of South America. Quaternary Science Reviews, 155, 37-49.

»Fernández, M. (2001). La Casa de Piedra de Ortega (Pcia. de Río Negro) I. La estratigrafía. Relaciones de La Sociedad Argentina de Antropología, XXVI, 261-284.

» Fernández, M. (2006). Los documentos escritos en la investigación arqueológica: análisis de un caso en Norpatagonia. Trabajo presentado en el II Encuentro de Investigadores. Fuentes y Problemas de la Investigación Histórica Regional. Santa Rosa, Argentina.

»Fernández, M. y Crivelli, E. (1999). La organización de la tecnología lítica de las primeras ocupaciones de la Casa de Piedra de Ortega. Xama, 12-14, 107-131.

» Fernández, M. y Crivelli, E. (2003). Producción lítica en Corralito (Depto. Pilcaniyeu, Pcia. De Río Negro). IV Congreso Argentino de Americanistas, II, 589-618.

»Fernández, M. y Ramos, M. (2009). Hallazgos especiales del sitio Casa de Piedra de Ortega (Pcia. de Río Negro): producción, funcionalidad y tendencias temporales. Anales de Arqueología y Etnología, 62, 223-287.

» Fernández, M. y Vitores, M. (2009). Distribución de la cerámica arqueológica en la cuenca superior y media del río Limay. En P. Azar, E. Cúneo y S. Rodriguez (Eds.), Tras las sendas de los Ancestros. Arqueología de Patagonia Terceras Jornadas de Historia de la Patagonia. [CD Rom]. San Carlos de Bariloche.

"Fernández, P. (2001). Procesamiento de guanaco en el sitio Campo Cerda 1 (Piedra Parada, Chubut, Argentina). En G. Mengoni Goñalons, D. Olivera y H. Yacobaccio (Eds.), El uso de los camélidos a través del tiempo (pp. 65-90). Buenos Aires: Del Tridente.

» Fernández, P. (2008). Taphonomy and zooarchaeology in the Neotropics: A view from northwestern Patagonian forest and steppe. Quaternary International, 180, 63-74.

» Fernández-Jalvo, Y. y Andrews, P. (2016). Atlas of taphonomic identifications. Nueva YorkLondres: Springer.

»Furlong, G. (1943). Entre los tehuelches de la Patagonia. Buenos Aires: Talleres Gráficos San Pablo.

» Grayson, D. (1984). Quantitative Zooarcheology. Topics in the Analysis of Archaeological Faunas. Nueva York: Academic Press. 
" Guillermo, A., Fernández, F. y Cordero, J. A. (2019). Explotación de Conepatus chinga (Carnivora, Mephitidae) en la cuenca superior y media del río Limay (noroeste de la Patagonia) durante el Holoceno tardío. Archaeofauna. International Journal of Archaeozoology, 28, 193-204

» Hajduk, A. y Albornoz, A. (1999). El sitio Valle Encantado I. Su vinculación con otros sitios: un esbozo de la problemática local diversa del Nahuel Huapi. En J. Belardi, P. Fernández, R. Goñi, G. Guráieb y M. De Nigris (Eds.), Soplando en el viento... Actas de las Terceras Jornadas de Arqueología de la Patagonia (pp. 371-391). Neuquén: Universidad del Comahue.

"Hajduk, A., Scartascini, F., Vargas, F. E. y Lezcano, M. (2018). Arqueología de la Isla Victoria, Parque Nacional Nahuel Huapi, Patagonia Argentina: actualización y perspectivas futuras. Intersecciones en Antropología, 19, 37-48.

» Hammer, Ø., Harper, D.A.T. y Ryan, P.D. (2001). PAST: Paleontological statistics software package for education and data analysis. Palaeontologia Electronica, 4(1), http://palaeoelectronica.org/2001_1/past/issue1_01.htm

" Havestadt, B. (1930). Viaje de fray Francisco Havestadt al Neuquén. Buenos Aires: Biblioteca del Suboficial.

" Kaufmann, C. (2009). Estructura de edad y sexo en guanaco: estudios actualísticos y arqueológicos en Pampa y Patagonia. Buenos Aires: Sociedad Argentina de Antropología.

» León, R., Bran, D., Collantes, M., Paruelo, J. M. y Soriano, A. (1998). Grandes unidades de vegetación de la Patagonia extra andina. Ecología Austral, 8, 125-144.

» Lyman, R. (1992). Prehistoric seal and sea-lion butchering on the southernnorthwest coast. American Antiquity, 57(2), 246-261.

» Lyman, R. (1994). Vertebrate Taphonomy. Cambridge: Cambridge University Press.

" Lyman, R. (2008). Quantitative Paleozoology. Cambridge: Cambridge University Press.

" Marean, C., Spencer, L., Blumenschine, R. y Capaldo, S. (1992). Captive Hyena Bone Choice and Destruction, the Shlepp Effect and Olduvai Archaeofaunas. Journal of Archaeological Science, 19, 101-121.

» Menéndez, F. [1791-1794] (1896). Diarios del P. Fr. Francisco Menéndez, Predicador General Apostólico del Colegio de Santa Rosa de Ocopa. Valparaíso: Niemeyer.

» Mengoni Goñalons, G. (1988). Análisis de materiales faunísticos de sitios arqueológicos. Xama, 1, 71-120.

" Mengoni Goñalons, G. (1999). Cazadores de guanacos de la estepa patagónica. Buenos Aires: Sociedad Argentina de Antropología.

" Mengoni Goñalons, G. (2006). Zooarqueología en la práctica: algunos temas metodológicos. Xama, 19, 83-113.

" Miotti, L. (2012). El uso de los recursos faunísticos entre los cazadores-recolectores de Patagonia: tendencias espacio/temporales de las estrategias durante el Holoceno. Archaeofauna. International Journal of Archaeozoology, 21, 137-160.

" Montalvo, C., Fernández, F. y Tallade, P. (2015). The role of Bubo virginianus magellanicus as rodent bone accumulator in archaeological sites. A case studyfor the Atuel River (Mendoza, Argentina). International Journal of Osteoarchaeology, 26, 974-986.

» Musters, G. [1871] (1964). Vida entre los patagones. Buenos Aires: Solar/Hachette.

»Pacheco Torres, V., Altamirano, A. y Guerra Porras, E. (1979). Guía Osteológica para Camélidos Sudamericanos. Lima: Universidad Nacional de Mayor de San Marcos. 
" Pardiñas, U. (1999a). Los roedores muroideos del Pleistoceno Tardío-Holoceno en la región pampeana [sector este] y Patagonia [República Argentina]. Aspectos taxonómicos, importancia bioestratigráfica y significación paleoambiental. (Tesis Doctoral inédita), Universidad Nacional de La Plata, Argentina.

» Pardiñas, U. (1999b). Tafonomía de microvertebrados en yacimientos arqueológicos de Patagonia (Argentina). Arqueología, 9, 265-340.

» Rindel, D. (2017). Explorando la variabilidad en el registro zooarqueológico de la provincia del Neuquén: tendencias cronológicas y patrones de uso antrópico. En F. Gord, R. Barberena, y V. Bernal (Eds.), El poblamiento del norte del Neuquén Estado actual del conocimiento (pp. 101-122). Buenos Aires: Aspha.

» Rosales, D. de. (1877). Historia general del Reyno de Chile. Flandes indiano. Valparaíso: Imprenta del Mercurio.

» Salemme, M. y Frontini, R. (2011). The exploitation of RHEIDAE in Pampa and Patagonia (Argentina) as recorded by chroniclers, naturalists and voyagers. Journal of Anthropological Archaeology, 30, 473-483.

»Shipman, P., Foster, G. y Schoeninger, M. (1984). Burnt Bones and Teeth: an Experimental Study of Color, Morphology, Crystal Structure an Shrinkage. Journal of Archaeology Science, 11, 307-325.

» Shipman, P. y Rose, J. (1983). Early hominid hunting, butchering and carcass-processing behaviors approaches to the fossil record. Journal of Antropologycal Archaeology, 2, 57-98.

» Silveira, M. y Cordero, J. A. (2014). Zooarqueología del sitio La Marcelina 1 (Provincia de Río Negro, Argentina). Atek Na, 4, 67-141.

» Teta, P., Andrade, A. y Pardiñas, U. (2005). Micromamíferos (Didelphimorphia y Rodentia) y paleoambientes del Holoceno tardío en la Patagonia noroccidental extraandina (Argentina). Archaeofauna. International Journal of Archaeozoology, 14, 183-197.

» Viedma, F. de. [1779] (1938). Carta de Francisco de Viedma al Virrey Vértiz del 4 de junio de 1779. Revista de La Biblioteca Nacional, 7, 504.

» Vignati, M. A. (1931). La armadura de un cacique patagón. Notas Preliminares Del Museo de La Plata, 1, 362-373.

»Vignati, M. A. (1964). Antecedentes para la protoetnografía del norte de la Patagonia. Boletín de La Academia Nacional de La Historia, 34, 493-525.

»Villarino, B. [1782-1783] (1972). Diario del piloto de la real Armada Don Basilio Villarino del reconocimiento que hizo del río Negro en la costa oriental de Patagonia en el año de 1782. Buenos Aires: Imprenta del Estado.

»Wolverton, S., Dombrosky, J. y Lyman, R. (2016). Practical Significance: Ordinal Scale Data and Effect Size in Zooarchaeology. International Journal of Osteoarchaeology, 26, $255-265$. 